\title{
Capital structure: The Italian market perspective
}

\author{
Maurizio Dallocchio ${ }^{1,2}$, Dimitrios Tzivelis ${ }^{3}$, Mario Antonio Vinzia ${ }^{2}$ \\ (1. Bocconi University of Milan, Milan 20136, Italy; 2. SDA Bocconi School of Management, Milan 20136, Italy; \\ 3. BC Partners, Milano 20121, Italy)
}

\begin{abstract}
This article first investigates the determinants of "capital structure" and the extent to which financial structure policy contributes to the creation of shareholder value in Italian companies through a survey of 76 CFOs of Italian listed non-financial companies, and revealed that the key driver is the quest for financial flexibility, necessary to combine effectively capital structure policy with the other two levers of value creation, investment policy and payout policy. These three value creation drivers are autonomous, but this empirical study reveals a clear hierarchy that links liability policy (capital structure and payout) to asset policy (investments) leading companies to make sub-optimal financial structure decisions that may not minimize the weighted average cost of capital, though ensuring the financial flexibility necessary to activate their principal lever of value creation, investment policy, effectively and without excessive constraints. A major finding in a subsequent benchmarking exercise is that Italian "family capitalism" affects corporate governance and therefore capital structure decisions. This finding may not be restricted to the Italian market, but could apply to all countries in which ownership structures are centered on very few shareholders with weak financial market control and where banks often play a crucial role in the governance of companies.
\end{abstract}

Key words: capital structure; dividend policy; corporate governance

\section{Introduction}

The extent to which financial structure policy contributes to the creation of shareholder value and what the main drivers of "capital structure" are have been the subject of numerous studies. Since the landmark article by Modigliani-Miller (1958), numerous scholars, including Graham and Harvey (2001) and Bancel and Mittoo (2002), have sought to examine capital structure policies organically, developing academic models and testing them through empirical research.

We have investigated this branch of financial studies in the belief that the most effective approach for investigating capital structure policy is to communicate directly with the principal actors involved, the CFOs, by means of a questionnaire that not only permits the analysis of the factors that most influence the funding preferences of listed Italian companies, but also provides a basis of comparison with similar international research.

By analyzing the responses provided by 76 listed non-financial companies, the authors have tested the applicability of the best known theoretical models to the Italian financial market, examined what factors most influence financial structure policy and the interrelation between investment and pay-out preferences and capital structure policies. The authors carried out a benchmarking exercise comparing the results of the Italian study with similar studies of US

Maurizio Dallocchio, Nomura Chair of Corporate Finance, Bocconi University, Past Dean, SDA Bocconi School of Management; research fields: corporate finance and corporate governance.

Dimitrios Tzivelis, investment associate at BC Partners \& researcher; research field: corporate finance.

Mario Antonio Vinzia, SDA Professor of the administration, control and corporate finance and real estate area, SDA Bocconi School of Management; research field: administration, control and corporate finance. 
markets and other European markets to identify essential similarities and differences, and to provide an interpretation of the decision-making dynamics of Italian companies on the topic of optimal financial structure.

The benchmarking exercise was also intended to highlight those influential factors which are possible key consideration not only for the Italian market, in that respect we have focused on corporate governance and ownership structure as an important capital structure determinants for all the countries where the ownership structures are often "block-holder based" and where banks often play a crucial role in the corporate governance.

\section{Questionnaire structure and characteristics}

\subsection{Concept and structure of the questionnaire}

The authors developed an initial set of 150 questions ultimately reduced to 77, in order to maximize the questionnaire redemption, through a selection process conducted together with scholars of SDA Bocconi and a few chief financial officers. The questionnaire was designed to investigate the main theoretical models, key or major empirical studies and the impact of recent major innovations (i.e., Basel II, IAS/IFRS, SOX and corresponding Italian law 262/05), while enabling, at the same time, a full benchmarking with other similar international studies.

The questionnaire (see Appendix A1 to Appendix A5) was divided into seven sections each of them representing a macro-area of inquiry: Section 1 "Information on the company"; Section 2 "Preferred forms of financing and financial structure targets"; Section 3 "Decisions regarding debt”; Section 4 "Decisions between short- and medium/long-term debt”; Section 5 "Decisions regarding liquidity”; Section 6 "Decisions regarding equity via capital increase”; Section 7 "Decisions between domestic and foreign financing”; Section 8 "Decisions regarding the issue of convertible loans”. Because of the few responses received to the questions in section 8 , they were omitted from the analysis.

To ensure full comparability with similar international studies, the authors based the questionnaire on Graham and Harvey (2001), the first paper on capital structure based on a survey which has been highly influential. For the response format, the authors adopted a Likert scale with four options (very important, important, less important, not important) to avoid a central tendency bias, as in the Graham and Harvey (2001) survey, in all sections with the exception of section 2.

The questionnaire was sent to the CFOs of the listed companies via e-mail, and the initial posting was followed by two reminders, also via e-mail, at 45-day intervals.

No "ex ante" sample selection was made-all the listed companies, except banks and insurance companies, were contacted without distinction, a total of 230 companies.

The response collection period lasted seven months (from December 2007 to June 2008), and 230 listed companies were contacted. Responses were obtained from 76 companies (8 via fax and 68 via e-mail), which gave the survey a response rate of 33\%, 40 of them blue chips, representing, at the time the survey was conducted, 53\% of the total market cap and $90 \%$ of the total market cap, excluding banks and insurance companies.

Table 1 shows the characteristics of the survey sample.

Table 1 The characteristics of the survey sample

\begin{tabular}{lc}
\hline Representativeness & Number \\
\hline Total number of companies & 76 \\
Market cap of the sample/Total market cap of market & $53 \%$ \\
(to be continued)
\end{tabular}


Market cap of the sample/Total market cap of the market (excl. financial sector companies)

$90 \%$ Stock market segment

$$
\text { Blue chip }
$$

Standard

Star

Tech star

Expandi

of the market (excl. financial sector companies)

\section{Sector}

Telecommunications, Tech. \& Media

Oil \& Gas

Utilities

Consumer goods

Industrial

Other

Revenues (€ millions)

$0<\mathrm{R}<100$
$100<\mathrm{R}<500$
$500<\mathrm{R}<1,000$
$\mathrm{R}>1,000$

$14 \quad 18.4$

$3 \quad 3.9$

$8 \quad 10.5$

$13 \quad 17.1$

$25 \quad 32.9$

$13 \quad 17.1$

Life cycle phase

\begin{tabular}{|c|c|c|}
\hline \multicolumn{3}{|l|}{ Startup } \\
\hline Fast growth & 24 & 31.6 \\
\hline Stability & 37 & 48.7 \\
\hline Maturity & 15 & 19.7 \\
\hline \multicolumn{3}{|l|}{ Control structure } \\
\hline Legal control by entrepreneur (s) or family & 34 & 44.7 \\
\hline De facto control by entrepreneur (s) or family & 8 & 10.5 \\
\hline Widely-owned (public company) & 10 & 13.2 \\
\hline Legal control by other company & 15 & 19.7 \\
\hline De facto control by other co. & 1 & 1.3 \\
\hline Other & 8 & 10.5 \\
\hline \multicolumn{3}{|l|}{ Positioning in the control structure } \\
\hline Parent of group of companies & 55 & 72.4 \\
\hline Subsidiary of a listed parent & 4 & 5.3 \\
\hline Subsidiary of an unlisted parent & 17 & 22.4 \\
\hline Not part of a group & 0 & 0.0 \\
\hline \multicolumn{3}{|l|}{ Rating } \\
\hline Greater than or equal to BBB & 23 & 30.3 \\
\hline Less than BBB & 7 & 9.2 \\
\hline Unrated & 46 & 60.5 \\
\hline \multicolumn{3}{|l|}{ Ratio consolidated net debt/ Market cap } \\
\hline Up to 1 & 70 & 92.1 \\
\hline 1.01 to 2.00 & 3 & 3.9 \\
\hline Greater than 2.00 & 3 & 3.9 \\
\hline \multicolumn{3}{|l|}{ Existence of stock option plans/stock grants } \\
\hline Yes, significant & 23 & 30.3 \\
\hline Yet, not significant & 21 & 27.6 \\
\hline No & 32 & 42.1 \\
\hline
\end{tabular}




\section{Preferred forms of financing and financial structure targets}

\subsection{Is financial structure policy a value creation lever?}

As the first question in the survey, it asked the CFOs whether their financial structure policy was a lever for creating shareholder value (Q1 in section 2). No fewer than 87\% responded that it was a value or key driver of value creation, a result derived in large part from the positive responses of the CFOs of the blue chips (94\%) and the companies with ratings (100\% of companies with ratings higher or lower than BBB) (see Table 2).

Table 2 Responses section 2-Preferred forms of financing and financial structure targets (\%)

\begin{tabular}{|c|c|c|c|c|c|c|c|c|c|c|c|c|c|c|c|c|}
\hline \multirow[b]{3}{*}{ Average market response } & \multirow[b]{3}{*}{ Q1 } & \multirow[b]{3}{*}{ Q2 } & \multicolumn{8}{|c|}{ Q3 } & \multicolumn{5}{|c|}{ Q4 } & \multirow[b]{3}{*}{ Q5 } \\
\hline & & & \multicolumn{2}{|c|}{$\begin{array}{c}\text { Investment } \\
\text { policy }\end{array}$} & \multicolumn{3}{|c|}{$\begin{array}{l}\text { Financial } \\
\text { structure }\end{array}$} & \multicolumn{3}{|c|}{ Payout policy } & \multirow{2}{*}{$\begin{array}{c}\begin{array}{c}\text { Self- } \\
\text { financing }\end{array} \\
1-2\end{array}$} & \multirow{2}{*}{$\begin{array}{c}\begin{array}{c}\text { Capital } \\
\text { increases }\end{array} \\
1-2\end{array}$} & \multirow{2}{*}{\begin{tabular}{|c|}
$\begin{array}{c}\text { Debt } \\
\text { via } \\
\text { banks }\end{array}$ \\
$1-2$ \\
\end{tabular}} & \multirow{2}{*}{$\begin{array}{c}\begin{array}{c}\text { Debt } \\
\text { via } \\
\text { market }\end{array} \\
1-2\end{array}$} & \multirow{2}{*}{$\begin{array}{c}\begin{array}{c}\text { Hybrid } \\
\text { forms }\end{array} \\
1-2 \\
\end{array}$} & \\
\hline & & & 2 & 3 & 1 & 2 & 3 & 1 & 2 & 3 & & & & & & \\
\hline Market & 87.2 & 63.0 & 56.513 .0 & 30.4 & 13.0 & 76.1 & 10.9 & 18.2 & 25.05 & 56.8 & 88.1 & 26.8 & 63.4 & 24.4 & 9.8 & 67.4 \\
\hline \multicolumn{17}{|l|}{ Stock market segment } \\
\hline Blue chip & 94.1 & 68.8 & 56.318 .8 & 25.0 & 6.7 & 86.7 & 6.7 & 13.3 & 13.37 & 73.3 & 82.4 & 23.5 & 58.8 & 35.3 & 5.9 & 88.2 \\
\hline Standard & 90.9 & 54.5 & $54.5 \quad 9.1$ & 36.4 & 0.0 & 90.0 & 10.0 & 10.0 & 40.05 & 50.0 & 81.8 & 30.0 & 70.0 & 30.0 & 20.0 & 60.0 \\
\hline Star & 88.9 & 66.7 & 55.611 .1 & 33.3 & 22.2 & 55.6 & 22.2 & 22.2 & 33.34 & 44.4 & 100.0 & 22.2 & 77.8 & 0.0 & 0.0 & 55.6 \\
\hline Other & 75.0 & 50.0 & $75.0 \quad 0.0$ & 25.0 & 0.0 & 75.0 & 25.0 & 25.0 & 25.05 & 50.0 & 100.0 & 50.0 & 25.0 & 25.0 & 25.0 & 50.0 \\
\hline \multicolumn{17}{|l|}{ Sector } \\
\hline Telecommunications, Tech. \& Media & 85.7 & 50.0 & 57.114 .3 & 28.6 & 0.0 & 85.7 & 14.3 & 14.3 & 42.9 & 42.9 & 100.0 & 28.6 & 42.9 & 28.6 & 14.3 & 50.0 \\
\hline Utilities & 100.0 . & 83.3 & 33.316 .7 & 50.0 & 16.7 & 83.3 & 0.0 & 16.7 & $0.0 \varepsilon$ & 83.3 & 66.7 & 50.0 & 33.3 & 16.7 & 0.0 & 83.3 \\
\hline Consumer goods & 100.0 . & 66.7 & 66.716 .7 & 16.7 & 0.0 & 100.0 & 0.0 & 20.0 & 20.0 & 60.0 & 83.3 & 20.0 & 100.0 & 40.0 & 0.0 & 66.7 \\
\hline Industrial & 76.9 & 53.8 & 66.78 .3 & 25.0 & 18.2 & 63.6 & 18.2 & 9.1 & 36.4 & 54.5 & 92.3 & 7.7 & 76.9 & 30.8 & 7.7 & 76.9 \\
\hline Other & 100. & 66.7 & 55.611 .1 & 33.3 & 0.0 & 77.8 & 22.2 & 22.2 & 22.25 & 55.6 & 88.9 & 44.4 & 55.6 & 11.1 & 22.2 & 66.7 \\
\hline \multicolumn{17}{|l|}{ Revenues ( $€$ millions) } \\
\hline $100<\mathrm{R}<500$ & 80.0 & 46.7 & $60.0 \quad 6.7$ & 33.3 & 14.3 & 57.1 & 28.6 & 21.4 & 35.7 & 42.9 & 86.7 & 28.6 & 64.3 & 14.3 & 0.0 & 46.7 \\
\hline $500<\mathrm{R}<1,000$ & 100.0 & 85.7 & 57.114 .3 & 28.6 & 0.0 & 100.0. & 0.0 & 14.3 & 28.6 & 57.1 & 100.0 & 42.9 & 71.4 & 28.6 & 28.6 & 66.7 \\
\hline $\mathrm{R}>1,000$ & 94.7 & 66.7 & 55.616 .7 & 27.8 & 5.9 & 88.2 & 5.9 & 11.8 & 17.67 & 70.6 & 84.2 & 21.1 & 57.9 & 31.6 & 10.5 & 89.5 \\
\hline \multicolumn{17}{|l|}{ Life cycle phase } \\
\hline Fast growth & 100.0 & 85.7 & 50.014 .3 & 35.7 & 7.1 & 85.7 & 7.1 & & 28.6 & 64.3 & 78.6 & 42.9 & 64.3 & 35.7 & 14.3 & 85.7 \\
\hline Stability & 77.8 & 58.8 & 64.711 .8 & 23.5 & 0.0 & 81.3 & 18.8 & 25.0 & 25.0 & 50.0 & 94.4 & 27.8 & 61.1 & 16.7 & 11.1 & 70.6 \\
\hline Maturity & 100. & 33.3 & 55.611 .1 & 33.3 & 25.0 & 62.5 & 12.5 & 12.5 & 25.0 & 62.5 & 88.9 & 0.0 & 62.5 & 25.0 & 0.0 & 44.4 \\
\hline \multicolumn{17}{|l|}{ Control structure } \\
\hline Legal control by entrepreneur(s) or family & 88.9 & 61.1 & $82.4 \quad 0.0$ & 17.6 & 0.0 & 93.3 & 6.7 & 20.0 & 6.77 & 73.3 & 94.4 & 11.8 & 82.4 & 17.6 & 5.9 & 66.7 \\
\hline De facto control by entrepreneur(s) or family & 80.0 & 60.0 & 60.020 .0 & 20.0 & 0.0 & 60.0 & 40.0 & 20.0 & 40.0 & 40.0 & 100.0 & 60.0 & 20.0 & 40.0 & 20.0 & 60.0 \\
\hline Widely-owned (public company) & 83.3 & 66.7 & 50.033 .3 & 16.7 & 16.7 & 66.7 & 16.7 & 16.7 & 33.3 & 50.0 & 83.3 & 33.3 & 66.7 & 50.0 & 0.0 & 66.7 \\
\hline Legal control by other company & 100.0 & 50.0 & $50.0 \quad 0.0$ & 50.0 & 16.7 & 83.3 & 0.0 & & 33.3 & 66.7 & 83.3 & 16.7 & 66.7 & 0.0 & 16.7 & 60.0 \\
\hline Other & 100.0 & 80.0 & $0 .(33.3$ & 66.7 & 16.7 & 66.7 & 16.7 & 16.7 & 50.03 & 33.3 & 66.7 & 50.0 & 33.3 & 33.3 & 16.7 & 100.0 \\
\hline \multicolumn{17}{|l|}{ Positioning in the control structure } \\
\hline Parent of group of companies & 87.5 & 58.1 & 54.816 .1 & 29.0 & 6.9 & 79.3 & 13.8 & 17.2 & 27.6 & 55.2 & 87.5 & 32.3 & 58.1 & 25.8 & 9.7 & 74.2 \\
\hline Subsidiary of an unlisted parent & 100.0 & 85.7 & 57.10 .0 & 42.9 & 14.3 & 71.4 & 14.3 & 14.3 & 28.6 & 57.1 & 85.7 & 14.3 & 71.4 & 28.6 & 14.3 & 57.1 \\
\hline \multicolumn{17}{|l|}{ Rating } \\
\hline Greater than or equal to BBB & 100.0 & 69.2 & 38.515 .4 & 46.2 & 7.7 & 76.9 & 15.4 & 23.1 & 23.1 & 53.8 & 84.6 & 23.1 & 30.8 & 23.1 & 23.1 & 75.0 \\
\hline Less than BBB & 100.0 & 50.0 & $0 .(66.7$ & 33.3 & 0.0 & 100.0 & 0.0 & & 66.7 & 33.3 & 66.7 & 0.0 & 100.0 & 0.0 & 0.0 & 66.7 \\
\hline Unrated & 84.0 & 60.0 & $75.0 \quad 4.2$ & 20.8 & 9.1 & 77.3 & 13.6 & 13.6 & 22.7 & 63.6 & 92.0 & 33.3 & 75.0 & 29.2 & 4.2 & 68.0 \\
\hline Existence of stock option plans/stock grants & & & & & & & & & & & & & & & & \\
\hline Yes, significant & 84.6 & 50.0 & 61.523 .1 & 15.4 & 7.7 & 76.9 & 15.4 & 15.4 & 23.1 & 61.5 & 84.6 & 7.7 & 69.2 & 46.2 & 15.4 & 69.2 \\
\hline Yet, not significant & 100.0 & 70.0 & $80.0 \quad 0.0$ & 20.0 & 0.0 & 100.0 & 0.0 & 10.0 & 10.0 & 80.0 & 100.0 & 30.0 & 70.0 & 40.0 & 0.0 & 60.0 \\
\hline No & 88.9 & 66.7 & 41.211 .8 & 47.1 & 13.3 & 66.7 & 20.0 & 20.0 & 40.0 & 40.0 & 83.3 & 41.2 & 52.9 & 0.0 & 11.8 & 76.5 \\
\hline
\end{tabular}

Financial structure policy was also viewed as a value or key driver, though with less emphasis, for 
bondholders (63\%, Q2 in section 2). In this case, the phase in the life cycle of the companies had a profound effect on the responses, with those in rapid growth (86\%) decidedly more convinced than those in stable (59\%) or mature (33\%) companies. This could be due to the fact that fast-growing companies are normally characterized by greater financial tension (considering their greater structural financial requirement to sustain the development process), so their financial structure decisions have a greater impact on the risk profile of their exposure to debt financers in comparison with stable or mature companies. The lower importance attributed to the second question is not surprising, since the advantages of a different form of asset financing are primarily perceived by shareholders because of the characteristic of their remuneration (residual claim).

Consistently, with the findings emerged from a survey on payout policies in the Italian market (Dallocchio, Tzivelis \& Vinzia, 2007), the responses given to Q1 revealed a strong conviction on the part of CFOs that "liability policies" (i.e., payout policy and capital structure policy) are value creation levers. Nevertheless, to determine the order of importance assigned to them in relation to investment policy, it is useful to comment on the responses to Q3 in section 2. As one might imagine, investment policy is deemed the primary driver of value creation, positioned as it is in first place (on a scale from 1 to 3 ) in $57 \%$ of the cases, followed by financial structure policy (ranked second in $76 \%$ of the cases) and payout policy (ranked third by $57 \%$ of the respondents). It is clearly evident for this sample, therefore, that in the corporate hierarchies, capital structure decisions are considered by CFOs to be more important than payout policy. This is not surprising and is consistent with indications in the previous study (Dallocchio, Tzivelis \& Vinzia, 2007), that the close role of capital structure policy in support of the principal driver of value creation, investments caused capital structure policy to receive greater attention from CFOs than payout policy. Consistently, Italian CFOs did not tend to modify capital structure decision just to maintain payout targets.

\subsection{Pecking Order Theory ${ }^{1}$ and preferred forms of financing}

The analysis of Q4 in section 2 indicates that the pecking order would be: self-financing (88\% of the sample ranked it as their first or second preferred source of financing), debt via the bank channel (63\%), capital increases (27\%), debt via the market (24\%) and, lastly, hybrid forms of financing such as convertible bonds (10\%). This order is quite in line with that of the Pecking Order Theory, the major difference being that on average the companies in our sample prefer to raise funds from the market through capital increase rather than through debt securities. This deviation could be attributed to the characteristics of our sample and more generally to the characteristics of the Italian corporate system. In fact, only companies with less than $€ 1,000$ million in revenues, though they represent $55 \%$ of our sample, provided such an order of preference. This could also be due to the fact that most, if not all, of the smaller companies derive their debt capital through the channel bank, while they draw on the market normally just for risk capital. If, on the other hand, only the responses of companies with more than $€ 1,000$ million in revenues are considered, the authors find that when they decide to borrow from the market, they issue debt, in total agreement with the Pecking Order Theory. As we shall clarify further on, this order of preference is not attributable, as in the pure academic model, to the different incidence of information asymmetry costs related to the different forms of financing but rather to different decision-making rationales.

\footnotetext{
${ }^{1}$ The Pecking Order Theory (Myers \& Majiluf, 1984) maintain that companies have no specific leverage targets but prefer funds generated internally, because outside financers (outsiders) suffer from information asymmetry with respect to the managers (insiders) and so seeking financing from the outside will mean obtaining financial resources "discounted" to the extent of this information asymmetry. When internal resources are lacking, however, companies prefer to utilize debt financing and only then equity, because of the higher incidence of cost of information asymmetry on the latter source of funding.
} 
Table 3 Responses section 2-Preferred forms of financing and financial structure targets (Cont., \%)

\begin{tabular}{|c|c|c|c|c|c|c|c|c|c|c|c|c|c|c|c|c|c|c|c|c|c|}
\hline \multirow[b]{3}{*}{ Average market response } & \multicolumn{4}{|c|}{ Q6 } & \multicolumn{14}{|c|}{ Q7 } & \multicolumn{3}{|c|}{ Q8 } \\
\hline & \multirow[t]{2}{*}{ A } & \multirow[t]{2}{*}{ B } & \multirow[t]{2}{*}{ C } & \multirow[t]{2}{*}{$\mathrm{D}$} & \multicolumn{2}{|c|}{$\begin{array}{l}\text { Net febt/ } \\
\text { Mkt cap }\end{array}$} & \multicolumn{2}{|c|}{$\begin{array}{l}\text { Net febt/ } \\
\text { PN }\end{array}$} & \multicolumn{2}{|c|}{$\begin{array}{l}\text { Net debt/ } \\
\text { EBITDA }\end{array}$} & \multicolumn{2}{|c|}{$\begin{array}{l}\text { EBITDA/ } \\
\text { FE }\end{array}$} & \multicolumn{2}{|c|}{$\begin{array}{l}\text { Credit rating } \\
\text { target }\end{array}$} & \multicolumn{4}{|c|}{$\begin{array}{c}\text { Net debt principal } \\
\text { compe- titors } \\
\text { other }\end{array}$} & \multirow{2}{*}{$\begin{array}{l}\text { Heavily } \\
\text { binding } \\
\text { over time }\end{array}$} & \multirow{2}{*}{$\begin{array}{l}\text { Reviewable } \\
\text { medium- } \\
\text { term }\end{array}$} & \multirow[t]{2}{*}{$\begin{array}{c}\text { Reviewable } \\
\text { short-term }\end{array}$} \\
\hline & & & & & $\mathrm{P}$ & S & $\mathrm{P}$ & S & $\mathrm{P}$ & S & $\mathrm{P}$ & S & $\mathrm{P}$ & S & $\mathrm{P}$ & S & $\mathrm{P}$ & S & & & \\
\hline Market & 46.2 & 23.1 & 30.8 & 15.4 & 9.7 & 22.6 & 48.4 & 19.4 & 80.6 & 6.5 & 19.4 & 19.4 & 25.8 & 19.4 & 6.5 & 22.6 & 6.5 & 6.5 & 31.3 & 37.5 & 31.3 \\
\hline \multicolumn{22}{|l|}{ Stock market segment } \\
\hline Blue chip & 0.0 & 0.0 & 50.0 & 50.0 & 6.7 & 26.7 & 33.3 & 13.3 & 80.0 & 0.0 & 0.0 & 20.0 & 46.7 & 13.3 & 6.7 & 20.0 & 6.7 & 6.7 & 35.7 & 28.6 & 35.7 \\
\hline Standard & 66.7 & 0.0 & 0.0 & 33.3 & 0.0 & 33.3 & 83.3 & 16.7 & 100.0 & 0.0 & 33.3 & 16.7 & 16.7 & 16.7 & 16.7 & 16.7 & 16.7 & 0.0 & 57.1 & 28.6 & 14.3 \\
\hline Star & 66.7 & 33.3 & 0.0 & 0.0 & 20.0 & 20.0 & 80.0 & 20.0 & 60.0 & 40.0 & 60.0 & 20.0 & 0.0 & 20.0 & 0.0 & 40.0 & 0.0 & 20.0 & 0.0 & 40.0 & 60.0 \\
\hline Other & - & - & - & - & 0.0 & 0.0 & 0.0 & 50.0 & 50.0 & 0.0 & 0.0 & 0.0 & 0.0 & 50.0 & 0.0 & 0.0 & 0.0 & 0.0 & 0.0 & 66.7 & 33.3 \\
\hline Sector & & & & & & & & & & & & & & & & & & & & & \\
\hline $\begin{array}{l}\text { Telecommunications, } \\
\text { Tech. \& media }\end{array}$ & 100.0 & 0.0 & 0.0 & 0.0 & 0.0 & 33.3 & 66.7 & 0.0 & 100.0 & 0.0 & 33.3 & 0.0 & 33.3 & 0.0 & 0.0 & 0.0 & 33.3 & 0.0 & 60.0 & 20.0 & 20.0 \\
\hline Utilities & 83.3 & 0.0 & 0.0 & 16.7 & 20.0 & 0.0 & 60.0 & 0.0 & 60.0 & 0.0 & 0.0 & 0.0 & 60.0 & 0.0 & 0.0 & 0.0 & 0.0 & 0.0 & 40.0 & 40.0 & 20.0 \\
\hline Consumer goods & 100.0 & 0.0 & 0.0 & 0.0 & 0.0 & 25.0 & 25.0 & 50.0 & 75.0 & 0.0 & 0.0 & 25.0 & 50.0 & 0.0 & 0.0 & 25.0 & 25.0 & 0.0 & 0.0 & 25.0 & 75.0 \\
\hline Industrial & 0.0 & 33.3 & 33.3 & 33.3 & 0.0 & 30.0 & 50.0 & 20.0 & 80.0 & 20.0 & 30.0 & 10.0 & 20.0 & 30.0 & 10.0 & 30.0 & 0.0 & 10.0 & 22.2 & 33.3 & 44.4 \\
\hline Other & 100.0 & 0.0 & 0.0 & 0.0 & 16.7 & 33.3 & 50.0 & 16.7 & 83.3 & 0.0 & 16.7 & 50.0 & 0.0 & 33.3 & 16.7 & 33.3 & 0.0 & 16.7 & 33.3 & 50.0 & 16.7 \\
\hline Revenues ( $€$ millions) & & & & & & & & & & & & & & & & & & & & & \\
\hline $100<\mathrm{R}<500$ & 60.0 & 20.0 & 0.0 & 20.0 & 14.3 & 28.6 & 57.1 & 42.9 & 71.4 & 28.6 & 57.1 & 14.3 & 0.0 & 28.6 & 0.0 & 42.9 & 0.0 & 14.3 & 12.5 & 25.0 & 62.5 \\
\hline $500<\mathrm{R}<1,000$ & 100.0 & 0.0 & 0.0 & 0.0 & 0.0 & 25.0 & 75.0 & 0.0 & 75.0 & 0.0 & 25.0 & 25.0 & 25.0 & 25.0 & 25.0 & 0.0 & 25.0 & 0.0 & 20.0 & 60.0 & 20.0 \\
\hline $\mathrm{R}>1,000$ & 0.0 & 0.0 & 50.0 & 50.0 & 5.9 & 23.5 & 41.2 & 11.8 & 82.4 & 0.0 & 0.0 & 17.6 & 41.2 & 11.8 & 5.9 & 17.6 & 5.9 & 5.9 & 43.8 & 31.3 & 25.0 \\
\hline Life cycle phase & & & & & & & & & & & & & & & & & & & & & \\
\hline Fast growth & 0.0 & 0.0 & 0.0 & 100.0 & 0.0 & 33.3 & 50.0 & 25.0 & 75.0 & 8.3 & 25.0 & 8.3 & 41.7 & 25.0 & 0.0 & 33.3 & 8.3 & 8.3 & 33.3 & 25.0 & 41.7 \\
\hline Stability & 33.3 & 33.3 & 0.0 & 33.3 & 8.3 & 25.0 & 50.0 & 8.3 & 100.0 & 0.0 & 16.7 & 25.0 & 16.7 & 16.7 & 16.7 & 16.7 & 8.3 & 8.3 & 38.5 & 30.8 & 30.8 \\
\hline Maturity & 75.0 & 0.0 & 25.0 & 0.0 & 25.0 & 0.0 & 50.0 & 25.0 & 25.0 & 25.0 & 0.0 & 25.0 & 25.0 & 0.0 & 0.0 & 0.0 & 0.0 & 0.0 & 0.0 & 75.0 & 25.0 \\
\hline Control structure & & & & & & & & & & & & & & & & & & & & & \\
\hline $\begin{array}{l}\text { Legal control by } \\
\text { entrepreneur(s) or family }\end{array}$ & 60.0 & 60.0 & 20.0 & 0.0 & 0.0 & 33.3 & 33.3 & 33.3 & 91.7 & 0.0 & 8.3 & 33.3 & 16.7 & 25.0 & 16.7 & 25.0 & 8.3 & 8.3 & 27.3 & 27.3 & 45.5 \\
\hline $\begin{array}{l}\text { De facto control by } \\
\text { entrepreneur(s) or family }\end{array}$ & 0.0 & 0.0 & 0.0 & 100.0 & 33.3 & 0.0 & 66.7 & 0.0 & 66.7 & 0.0 & 33.3 & 0.0 & 0.0 & 0.0 & 0.0 & 33.3 & 33.3 & 0.0 & 50.0 & 25.0 & 25.0 \\
\hline $\begin{array}{l}\text { Widely-owned (public } \\
\text { company) }\end{array}$ & 50.0 & 0.0 & 0.0 & 50.0 & 25.0 & 0.0 & 25.0 & 25.0 & 50.0 & 25.0 & 25.0 & 0.0 & 25.0 & 0.0 & 0.0 & 0.0 & 0.0 & 0.0 & 0.0 & 50.0 & 50.0 \\
\hline $\begin{array}{l}\text { Legal control by other } \\
\text { company }\end{array}$ & - & - & - & - & 0.0 & 0.0 & 100.0 & 0.0 & 33.3 & 33.3 & 33.3 & 33.3 & 33.3 & 33.3 & 0.0 & 0.0 & 0.0 & 0.0 & 25.0 & 75.0 & 0.0 \\
\hline Other & - & - & - & - & 0.0 & 50.0 & 66.7 & 0.0 & 100.0 & 0.0 & 16.7 & 0.0 & 66.7 & 16.7 & 0.0 & 33.3 & 0.0 & 16.7 & 50.0 & 16.7 & 33.3 \\
\hline $\begin{array}{l}\text { Positioning in the control } \\
\text { structure }\end{array}$ & & & & & & & & & & & & & & & & & & & & & \\
\hline $\begin{array}{l}\text { Parent of group of } \\
\text { companies }\end{array}$ & 40.0 & 20.0 & 20.0 & 20.0 & 8.7 & 30.4 & 52.2 & 17.4 & 91.3 & 4.3 & 21.7 & 17.4 & 30.4 & 17.4 & 8.7 & 26.1 & 4.3 & 8.7 & 37.5 & 29.2 & 33.3 \\
\hline $\begin{array}{l}\text { Subsidiary of an unlisted } \\
\text { parent }\end{array}$ & 50.0 & 0.0 & 0.0 & 50.0 & 0.0 & 0.0 & 25.0 & 25.0 & 25.0 & 25.0 & 0.0 & 25.0 & 0.0 & 25.0 & 0.0 & 0.0 & 25.0 & 0.0 & 0.0 & 50.0 & 50.0 \\
\hline Rating & & & & & & & & & & & & & & & & & & & & & \\
\hline $\begin{array}{l}\text { Greater than or equal to } \\
\text { BBB }\end{array}$ & 66.7 & 0.0 & 0.0 & 33.3 & 11.1 & 22.2 & 55.6 & 0.0 & 77.8 & 0.0 & 11.1 & 0.0 & 44.4 & 22.2 & 11.1 & 11.1 & 11.1 & 0.0 & 55.6 & 33.3 & 11.1 \\
\hline Less than BBB & - & - & - & - & 0.0 & 0.0 & 50.0 & 0.01 & 100.0 & 0.0 & 0.0 & 0.0 & 50.0 & 0.0 & 0.0 & 0.0 & 0.0 & 0.0 & 0.0 & 50.0 & 50.0 \\
\hline Unrated & 40.0 & 20.0 & 20.0 & 20.0 & 5.9 & 29.4 & 47.1 & 29.4 & 76.5 & 11.8 & 23.5 & 29.4 & 17.6 & 17.6 & 5.9 & 29.4 & 5.9 & 11.8 & 22.2 & 33.3 & 44.4 \\
\hline $\begin{array}{l}\text { Existence of stock option } \\
\text { plans/stock grants }\end{array}$ & & & & & & & & & & & & & & & & & & & & & \\
\hline Yes, significant & 50.0 & 25.0 & 0.0 & 25.0 & 11.1 & 44.4 & 44.4 & 22.2 & 66.7 & 11.1 & 11.1 & 22.2 & 33.3 & 11.1 & 0.0 & 33.3 & 11.1 & 11.1 & 22.2 & 44.4 & 33.3 \\
\hline Yet, not significant & 0.0 & 0.0 & 50.0 & 50.0 & 0.0 & 16.7 & 33.3 & 33.3 & 66.7 & 0.0 & 16.7 & 16.7 & 16.7 & 16.7 & 0.0 & 16.7 & 16.7 & 0.0 & 50.0 & 16.7 & 33.3 \\
\hline No & 100.0 & 0.0 & 0.0 & 0.0 & 7.7 & 15.4 & 61.5 & 7.7 & 92.3 & 7.7 & 23.1 & 15.4 & 30.8 & 23.1 & 15.4 & 15.4 & 0.0 & 7.7 & 28.6 & 35.7 & 35.7 \\
\hline
\end{tabular}

Notes: A = Company structurally liquid; B = Uses debt only when self-financing is insufficient; C = Financial structure decisions are made based on market opportunities; $\mathrm{D}$ = Strong variability (growth, results, cash flow, etc.) precludes the setting of targets. 


\subsection{The trade-off theory ${ }^{2}$ and the use of financial targets}

An analysis of the responses to Q5 in section 2 revealed that $67 \%$ of the sample stated that, when making their financial structure decisions, companies measure themselves against one or more targets. Particularly attentive to this aspect are the blue chip companies (88\%), those with revenues in excess of $€ 1000$ million vs. smaller firms ( $90 \%$ vs. $67 \%$ of the companies with revenues between $€ 1,000$ and $€ 500$ million and $47 \%$ of those with sales between $€ 100$ and $€ 500$ million), the fast-growing companies vs. the mature ones (86\% vs. 44\%) and companies with investment-grade ratings vs. speculative grade and unrated companies (75\% vs. 67\% and 68\%).

It comes as no surprise that companies in the blue chip segment and those with more than one thousand million in revenues are more inclined to set specific objectives in the area of financial structure. This, in fact, can be explained by the need for more sophisticated decision-making processes in larger, more complex companies and, particularly in the case of the blue chips, by a frequent need to communicate targets to the market (sometimes driven by the financial analysts). Analogically, it is not surprising that companies with investment grade ratings are more cautious in setting and meeting financial structure targets, given their understandable desire to maintain their credit ratings.

Interestingly, the life cycle phase seems to be influential on the importance attributed to the adoption of financial targets. This could be due to the fact that fast-growing companies have greater need of discipline and caution in their financial decisions, because it is more difficult for them to access the financial resources necessary to sustain the growth process than for stable, mature companies. In fact, if we analyze the responses to Q6 in section 2, which investigates the reasons why companies decide not to utilize capital structure targets, $75 \%$ of the mature companies that responded negatively to Q5 in section 2 advanced as a justification for the fact that their companies are structurally liquid. Even from a more general perspective, this type of response was the most common one (46\%), followed by the fact that market opportunities must guide financing decisions (31\%), by the decision to utilize debt only when self-financing is insufficient (23\%) and, lastly, by the rationale that strong variability (of growth, results, cash flow, etc.) makes it impossible to set targets (15\%, which rises up to $100 \%$ in the case of fast growing companies) (see Table 3).

\subsection{Financial targets and their time value}

With Q7 and Q8 in section 2, the authors investigated the characteristics of the financial structure targets, first identifying them and then circumscribing their time value.

As an analysis of the responses to Q7 revealed, the primary targets decidedly most widespread among listed companies are Net Debt/EBITDA (81\%), strongly representative of the ability of the companies to cover their debt with the cash flows generated by operations, followed by Net Debt/Equity (48\%), the classic indicator of balance sheet structure. These are the ratios, especially the former, frequently used by analysts to evaluate companies and are also commonly used as covenants in financing operations. Secondly or next, the Credit Rating Target (26\%, but as much as $47 \%$ and $41 \%$ respectively for the blue chips and for companies with more than $€ 1,000$ million in revenues, rising to the number two target in order of importance), EBITDA/Financial expense (19\%) and, lastly, Net Debt/Market Cap (10\%) and the Net Debt of principal competitors (7\%). These observations suggest that companies place greater faith in accounting ratios than in market values. This disharmony with the theory that bases leverage decisions on market values can be explained, in the authors' view, by adherence to the

\footnotetext{
${ }^{2}$ According to the Trade-off Theory (Scott, 1976; Modigliani \& Miller, 1963; Miller, 1977), companies have optimal leveraging targets, obtained by offsetting the tax advantages of deductible borrowing costs (tax shields) and bankruptcy costs (cost of financial distress).
} 
analytical methodology of the rating companies and lending banks and to the more difficult planning of targets that use market values, given their greater volatility, and thus a more frequent need to rebalance them.

Regarding secondary targets, the two that obtained greatest favor are Net Debt/Market Cap (voted by 25\% of the companies that stated they had targets) and Net Debt of principal competitors (23\%), followed by Net Debt/Equity, EBITDA/Financial expense and Credit rating target, all with 19\%. The observation that the secondary target most frequently used is Net Debt/Market Cap reduces, though only partially, the disharmony between academic theory and practice: Though companies focus primarily on accounting indicators, in fact, some of them still monitor the impact of their financial structure decisions on the indicator used by analysts to compute the cost of capital and consequently the enterprise value of the company.

With Q8, the authors also sought to understand how much these financial structure targets are binding over time. An analysis of the responses reveals three distinct groups. For 31\% of the companies, the target is strongly binding over time; For 38\%, it can be reviewed over the medium term (e.g., 3 years); While for 31\%, it can be reviewed short-term. No definite average term emerges, therefore, but the type of constraint must be sought in each case in the specific characteristics of each company. It is useful to point out that the duration of the targets is not synonymous with the degree to which it is binding. In fact, as showed in the next 2 paragraph, even the companies that said they review their targets in the short term showed a strong propensity to defend them. Thus, a target of shorter duration in time is no less capable of guiding financial structure decisions: It is just more likely to be subject to review because of the greater frequency of changes in the internal and external conditions in which the companies operate.

In conclusion, there will be three observations. The first is that companies with more than $€ 1,000$ million in revenues, i.e. those that, as we have seen, seem to make more frequent use of financial structure targets, are those that most regarded those targets as strongly binding over time (44\%), whereas the smaller companies (revenues between $€ 500$ and $€ 100$ million), in most cases, review their targets in the short term (63\%); The second is that fast-growing companies review their targets more frequently (42\%) than stable (31\%) and mature companies (25\%), consistent with the greater tendency for change in their financial situation; The third is that companies with investment grade ratings, in most cases, perceive their targets as strongly binding over time (56\%) vs. speculative grade $(0 \%)$ and unrated (22\%) companies, which review their targets more often in the short term.

\section{Debt}

The analysis of hierarchies in terms of value creation among investment policy, dividends and financial structure, together with the preference expressed regarding acceptable sources and any targets on which to base optimal financial structure, then, the authors will analyze the decisions regarding debt and liquidity (see Table 4 and Table 5).

\subsection{Financial flexibility}

Analysis of the responses to the questions in the section on debt and liquidity policies indicates that financial flexibility is the most important principle (73\% “important” or “very important” to Q1 in section 3 and 71\% Q1 in section 5) underlying the choice of financial structure. The importance of financial flexibility emerges from many responses. Primarily, it is regarded as a means for enabling the company to undertake profitable investment projects (including M\&A operations) without the constraints that excessive leverage can impose. As long ago as 1969, Donaldson underscored the importance of "financial mobility", which he defined as the ability to direct the 
use of financial resources consistent with the evolution of corporate decisions in response to changes in the company and its environment. There has been a considerable support for this idea, including Graham and Harvey (2001), who define financial flexibility as a means of preserving the debt capacity necessary to sustain investments and acquisitions, and Peyer and Shivdasan (2001), who state that heavy indebtedness and the consequent onerous servicing of the debt, can lead to the loss of investments that create value. Therefore, it follows that the under-dimensioning of debt, and the consequent non-optimization of the weighted average cost of capital, may be more than offset by the possibility of not letting profitable investment opportunities escape.

Table 4 Responses section 3-Decisions regarding debt

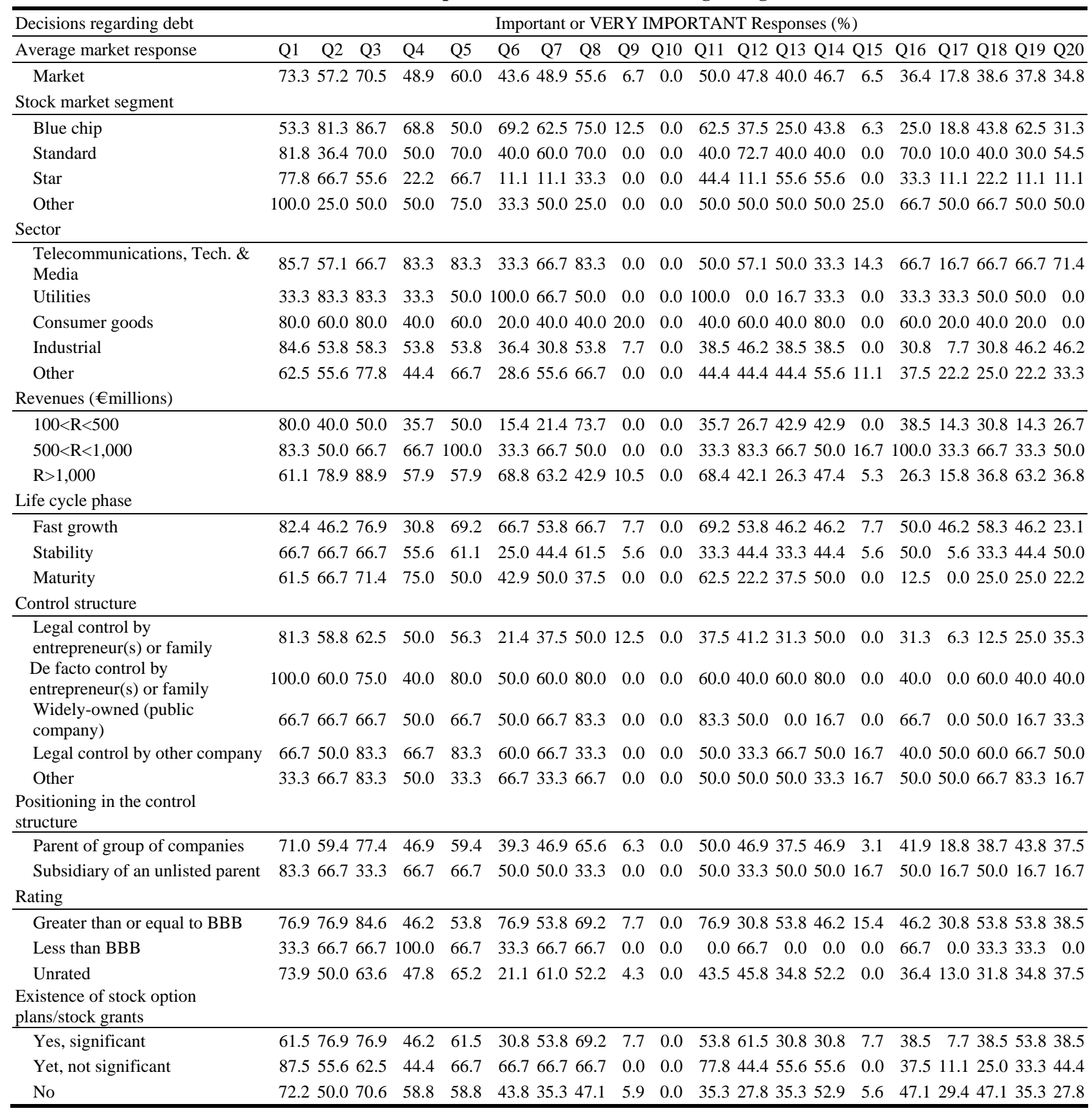


Table 5 Responses section 5-Decisions regarding liquidity

\begin{tabular}{|c|c|c|c|c|c|c|c|c|}
\hline \multirow{2}{*}{$\begin{array}{l}\text { Decisions regarding liquidity } \\
\text { Average market response }\end{array}$} & \multicolumn{8}{|c|}{ Important or very important responses (\%) } \\
\hline & Q1 & Q2 & Q3 & Q4 & Q5 & Q6 & Q7 & Q8 \\
\hline Market & 71.1 & 37.8 & 31.8 & 18.2 & 22.2 & 17.8 & 8.9 & 44.4 \\
\hline \multicolumn{9}{|l|}{ Stock market segment } \\
\hline Blue chip & 68.8 & 43.8 & 37.5 & 18.8 & 18.8 & 12.5 & 6.3 & 25.0 \\
\hline Standard & 72.7 & 18.2 & 20.0 & 10.0 & 27.3 & 18.2 & 27.3 & 63.6 \\
\hline Star & 88.9 & 55.6 & 33.3 & 22.2 & 33.3 & 44.4 & 0.0 & 55.6 \\
\hline Other & 50.0 & 50.0 & 0.0 & 25.0 & 25.0 & 0.0 & 0.0 & 50.0 \\
\hline \multicolumn{9}{|l|}{ Sector } \\
\hline Telecommunications, Tech. \& Media & 85.7 & 40.0 & 16.7 & 0.0 & 57.1 & 14.3 & 42.9 & 71.4 \\
\hline Utilities & 80.0 & 57.1 & 60.0 & 40.0 & 0.0 & 20.0 & 0.0 & 60.0 \\
\hline Consumer goods & 66.7 & 33.3 & 16.7 & 16.7 & 33.3 & 16.7 & 0.0 & 33.3 \\
\hline Industrial & 84.6 & 38.5 & 38.5 & 15.4 & 15.4 & 23.1 & 7.7 & 38.5 \\
\hline Other & 44.4 & 33.3 & 11.1 & 22.2 & 22.2 & 22.2 & 0.0 & 33.3 \\
\hline \multicolumn{9}{|l|}{ Revenues ( $€$ millions) } \\
\hline $100<\mathrm{R}<500$ & 80.0 & 33.3 & 21.4 & 7.1 & 26.7 & 33.3 & 6.7 & 66.7 \\
\hline $500<\mathrm{R}<1,000$ & 100.0 & 57.1 & 28.6 & 42.9 & 42.9 & 14.3 & 14.3 & 42.9 \\
\hline $\mathrm{R}>1,000$ & 50.0 & 38.9 & 33.3 & 16.7 & 16.7 & 11.1 & 11.1 & 27.8 \\
\hline \multicolumn{9}{|l|}{ Life cycle phase } \\
\hline Fast growth & 78.6 & 42.9 & 50.0 & 28.6 & 21.4 & 14.3 & 0.0 & 50.0 \\
\hline Stability & 77.8 & 38.9 & 22.2 & 16.7 & 22.2 & 11.1 & 16.7 & 38.9 \\
\hline Maturity & 50.0 & 37.5 & 0.0 & 0.0 & 37.5 & 50.0 & 12.5 & 50.0 \\
\hline \multicolumn{9}{|l|}{ Control structure } \\
\hline Legal control by entrepreneur(s) or family & 72.2 & 27.8 & 29.4 & 17.6 & 11.1 & 16.7 & 11.1 & 27.8 \\
\hline De facto control by entrepreneur(s) or family & 60.0 & 20.0 & 20.0 & 0.0 & 40.0 & 40.0 & 20.0 & 60.0 \\
\hline Widely-owned (public company) & 83.3 & 66.7 & 16.7 & 0.0 & 16.7 & 0.0 & 0.0 & 33.3 \\
\hline Legal control by other company & 40.0 & 60.0 & 0.0 & 20.0 & 40.0 & 40.0 & 20.0 & 80.0 \\
\hline Other & 66.7 & 50.0 & 83.3 & 66.7 & 50.0 & 33.3 & 0.0 & 66.7 \\
\hline \multicolumn{9}{|l|}{ Positioning in the control structure } \\
\hline Parent of group of companies & 71.9 & 40.6 & 28.1 & 18.8 & 25.0 & 12.5 & 9.4 & 40.6 \\
\hline Subsidiary of an unlisted parent & 71.4 & 42.9 & 28.6 & 14.3 & 14.3 & 42.9 & 0.0 & 57.1 \\
\hline \multicolumn{9}{|l|}{ Rating } \\
\hline Greater than or equal to BBB & 92.3 & 61.5 & 30.8 & 23.1 & 30.8 & 7.7 & 15.4 & 61.5 \\
\hline Less than BBB & 66.7 & 33.3 & 0.0 & 0.0 & 66.7 & 33.3 & 0.0 & 66.7 \\
\hline Unrated & 62.5 & 29.2 & 30.4 & 17.4 & 16.7 & 25.0 & 8.3 & 33.3 \\
\hline \multicolumn{9}{|l|}{ Existence of stock option plans/stock grants } \\
\hline Yes, significant & 76.9 & 46.2 & 23.1 & 0.0 & 23.1 & 0.0 & 7.7 & 38.5 \\
\hline Yet, not significant & 66.7 & 44.4 & 33.3 & 11.1 & 11.1 & 33.3 & 0.0 & 22.2 \\
\hline No & 72.2 & 33.3 & 29.4 & 35.3 & 33.3 & 27.8 & 16.7 & 61.1 \\
\hline
\end{tabular}

As evidence for this statement, the following companies were found to be highly attentive to financial flexibility: companies with revenues between $€ 100$ and $€ 500$ million (80\% Q1 in section 3 and 80\% Q1 in section 5) and those with revenues between $€ 500$ and $€ 1,000$ million (83\% Q1 in section 3 and 100\% Q1 in section 5), reasonably because they are structurally less capable of generating sufficient cash flows to sustain their investment projects and repay their debt. This is supported by the fact that these two types of company were also those that were more attentive to the volatility of cash flows and future income. Overall, therefore, it became evident that the policies of indebtedness and financial structure in general, are subordinate to investment decisions, 
since debt tends to be under-dimensioned with respect to the optimal level in order to ensure the necessary flexibility - This interpretation is consistent with the hierarchies expressed in the preceding section.

The second reason why financial flexibility is important is that it affords the possibility of exploiting temporary favorable situations in the credit market. This was cited as the third most important factor by $60 \%$ of the respondents, (Q5 in section 3) who considered the current level of interest rates as an important or very important factor. Similarly, when commenting on equity policies in section 4: $60 \%$ of the companies seek to exploit windows of opportunity, and a necessary condition for doing this is having sufficient financial flexibility to seize these opportunities (Q2 in section 6).

Another purpose of flexibility is to ensure the ability to maintain current and expected dividend levels (Q11 in section 3). This, in fact, is how $50 \%$ of the CFOs responded concerning indebtedness policies (68\% for the largest companies with revenues exceeding $€ 1000$ million, and $77 \%$ for investment grade firms) and 38\% liquidity policy (Q2 in section 5) selected or cited as the third most important factor. Particularly attentive to this aspect are utilities and public companies, which, in both cases, manifested the highest percentages in their respective categories (100\% and $83 \%$ on Q11, and $57 \%$ and $67 \%$ on Q2, respectively). Regarding the former, the investors who purchase their stock are generally "dividends hunters" seeking to realize most of their returns through dividends, so it is no surprise that these companies strive to have the resources available to distribute to shareholders. Likewise, the particular attention of public companies is not surprising, an observation consistent with our previous study (Dallocchio, Tzivelis \& Vinzia, 2007), where we found that in Italy, the public companies are rather more cautious about cutting dividends (and a necessary condition for exercising this caution is having sufficient financial resources available), since the dividend has a stronger role as an instrument of control for the shareholders.

The fact that capital structure choices aim to support both payout and, mainly, investment decisions does not imply that capital structure policy is simply a derivation of the investment and payout policies. The three "levers" of value creation still retain their capability to independently create value, even if they are utilized in synchronization with each other, with a preference for investment policy as the main value driver. In fact, while for payout policies, this independent ability to create value lies, according to the CFOs, in their signaling effect, in the case of capital structure policies, it must be sought in the minimization of the cost of financing sources, i.e., the weighted average cost of capital. Nevertheless, an analysis of CFO responses reveals that these two levers must offset their independent function with the need to have the financial flexibility necessary to "trigger" the principal lever of value creation, which is investment policy, effectively and without excessive restrictions.

Furthermore, the evidence that the second most selected factor (Q3 in section 3) is the desire to maintain financial structure targets (71\%) which must not be viewed as a sign of rigidity, and thus, contrary to the principle of flexibility described — quite the opposite. When they are formulated, financial structure targets balance the various tradeoffs that companies must manage, particularly to adequately use the debt lever to minimize the cost of capital, while providing sufficient flexibility for operational management. It is important to note that, if we exclude the companies that stated they had no targets, the percentage rises to $87 \%$, without major differences between those that stated they review their targets short-term and those that review them long-term, demonstrating that targets, for companies that use them, have the same ability to guide regardless of their time span. It is also interesting to note that the companies that expressed the greatest propensity to use financial targets, i.e., the fast-growing ones, the largest ones, and the investment grade ones, are also those that take the most care to defend them. 


\subsection{Tax shields, cost of financial distress and trade-off theory}

In the previous section, the authors observed that most of the companies actually have financial structure targets consistent with trade-off theory. An analysis of the responses indicates that this is not attributable merely to offsetting the tax advantages of debt vs. bankruptcy costs, as in the theoretical model, but, as already noted, to a broader balancing that considers not only minimizing the cost of capital, but also the need to have adequate financial flexibility.

The tax advantages deriving from the use of debt (Q4 in section 3) undoubtedly plays a role in indebtedness decisions: $49 \%$ feel that the tax deductibility of interest is a relevant factor, which gives rise to the conviction on the part of CFOs (57\%) that debt is the least costly form of financing (Q2 in section 3), a conviction particularly strong among the blue chips (81\%), larger companies (79\%) and more highly rated companies (77\%). This focus on the lower cost of debt as a form of "outside" financing may indicate that companies wish to minimize their cost of capital by using this form. The "cost of financial distress" would seem to be less important in relation to the question of how much the risk of insolvency weighs in indebtedness decisions, in fact, only $7 \%$ of the sample rated it as important (Q15 in section 3). When the responses in the questionnaire as a whole are taken into account, it appears that the companies are extremely attentive to the disadvantages caused by an excessive use of leverage. This is specifically supported by the importance assigned to the volatility of future income and cash flows (56\%), factors that typically increase the risk of insolvency, when taking debt decisions (Q8 in section 3).

Pointing in that same direction are the responses regarding the weight of credit ratings, another key for interpreting the risk of insolvency (Q6 and Q7 in section 3). At first glance, the responses seem neutral, since only $44 \%$ (rating agencies, 77\% for investment grade) and 49\% (bank rating, 67\% for speculative grade) assign a significant weight to this factor. However, owing to the fact that the $92 \%$ of respondents have alternatively chosen the agency rating or the banking rating, we could consider the credit rating factor in aggregate without breaking it down into the two categories. As a result of this, credit ratings are deemed to be a very important driver in indebtedness decisions. In this regard, it is important to note that the speculative grade companies, besides those that displayed greater preference for using bank debt (100\%) are also those particularly careful not to alter their credit ratings, partly by complying with financial covenants. This could be interpreted as the conviction regarding the smaller credit risk spread applied by the banking channel compared to the market, which is more affected by the information asymmetry effect. Further evidence for the concern over credit risk is that $44 \%$ of the sample stated they wished to reassure their shareholders regarding the company's low risk profile through their liquidity policies (Q8 in section 3, the second most important factor), and the fact that $63 \%$ of the respondents prefer medium/long-term debt because it is generally not revocable, and thus more secure (Q6 in section 4, the second most selected factor), although 92\% of the sample has a Net Debt/Market Cap ratio of less than 1 and only 28\% find furnishing adequate guarantees to the banks to be important or very important (Q5 in section 4) (see Table 6).

Lastly, it is interesting to note, as also supported by findings reported in section 4 , that companies seem to be keen not to deviate from financial structure targets with debt rather than with equity, demonstrating a conviction that the "payoffs" deriving from optimization of the capital structure are asymmetrical, in the sense that the costs associated with having lower-than-optimal debt are still lower than those associated with a higher debt level. 
Table 6 Responses section 4-Decisions between short- and medium/long-term debt

\begin{tabular}{|c|c|c|c|c|c|c|}
\hline \multirow{2}{*}{$\begin{array}{l}\text { Decisions regarding short- and medium/long term debt } \\
\text { Average market response }\end{array}$} & \multicolumn{6}{|c|}{ Important or very important responses (\%) } \\
\hline & Q1 & Q2 & Q3 & Q4 & Q5 & Q6 \\
\hline Market & 45.7 & 95.7 & 11.1 & 8.7 & 28.3 & 63.0 \\
\hline \multicolumn{7}{|l|}{ Stock market segment } \\
\hline Blue chip & 31.3 & 93.8 & 18.8 & 0.0 & 18.8 & 75.0 \\
\hline Standard & 36.4 & 100.0 & 0.0 & 9.1 & 27.3 & 63.6 \\
\hline Star & 55.6 & 100.0 & 11.1 & 0.0 & 22.2 & 44.4 \\
\hline Other & 75.0 & 75.0 & 25.0 & 50.0 & 50.0 & 75.0 \\
\hline \multicolumn{7}{|l|}{ Sector } \\
\hline Telecomunications, Tech. \& Media & 42.9 & 85.7 & 16.7 & 0.0 & 28.6 & 71.4 \\
\hline Utilities & 33.3 & 100.0 & 16.7 & 0.0 & 0.0 & 83.3 \\
\hline Consumer goods & 40.0 & 80.0 & 0.0 & 20.0 & 0.0 & 40.0 \\
\hline Industrial & 38.5 & 100.0 & 7.7 & 0.0 & 15.4 & 69.2 \\
\hline Other & 55.6 & 100.0 & 22.2 & 22.2 & 66.7 & 55.6 \\
\hline \multicolumn{7}{|l|}{ Revenues ( $€$ millions) } \\
\hline $100<\mathrm{R}<500$ & 53.3 & 53.3 & 21.4 & 13.8 & 20.0 & 46.7 \\
\hline $500<\mathrm{R}<1,000$ & 83.3 & 100.0 & 16.7 & 33.3 & 50.0 & 83.3 \\
\hline $\mathrm{R}>1,000$ & 36.8 & 94.7 & 15.8 & 0.0 & 21.1 & 68.4 \\
\hline \multicolumn{7}{|l|}{ Life cycle phase } \\
\hline Fast growth & 46.2 & 92.3 & 7.7 & 23.1 & 23.1 & 92.3 \\
\hline Stability & 50.0 & 94.4 & 16.7 & 0.0 & 27.8 & 55.6 \\
\hline Maturity & 22.2 & 100.0 & 12.5 & 0.0 & 22.2 & 44.4 \\
\hline \multicolumn{7}{|l|}{ Control structure } \\
\hline Legal control by entrepreneur(s) or family & 29.4 & 94.1 & 0.0 & 0.0 & 17.6 & 52.9 \\
\hline De facto control by entrepreneur(s) or family & 60.0 & 80.0 & 40.0 & 0.0 & 60.0 & 20.0 \\
\hline Widely-owned (public company) & 66.7 & 100.0 & 16.7 & 16.7 & 0.0 & 83.3 \\
\hline Legal control by other company & 50.0 & 100.0 & 16.7 & 33.3 & 50.0 & 83.3 \\
\hline Other & 33.3 & 100.0 & 16.7 & 0.0 & 16.7 & 100.0 \\
\hline \multicolumn{7}{|l|}{ Positioning in the control structure } \\
\hline Parent of group of companies & 46.9 & 93.8 & 12.5 & 6.3 & 25.0 & 62.5 \\
\hline Subsidiary of an unlisted parent & 33.3 & 100.0 & 16.7 & 16.7 & 33.3 & 66.7 \\
\hline \multicolumn{7}{|l|}{ Rating } \\
\hline Greater than or equal to BBB & 46.2 & 100.0 & 23.1 & 7.7 & 30.8 & 61.5 \\
\hline Less than BBB & 33.3 & 100.0 & 0.0 & 33.3 & 0.0 & 66.7 \\
\hline Unrated & 41.7 & 91.7 & 8.7 & 4.2 & 25.0 & 66.7 \\
\hline \multicolumn{7}{|l|}{ Existence of stock option plans/stock grants } \\
\hline Yes, significant & 30.8 & 92.3 & 7.7 & 0.0 & 7.7 & 69.2 \\
\hline Yet, not significant & 33.3 & 100.0 & 11.1 & 11.1 & 33.3 & 77.8 \\
\hline No & 55.6 & 94.4 & 17.6 & 11.1 & 33.3 & 55.6 \\
\hline
\end{tabular}

\subsection{Information asymmetries and Pecking Order Theory}

As described in section 2, Italian CFOs indicate a tendency to favor internal sources and to prefer bank debt, within the external sources, to market operations in general. This behavior model has a strong analogy with the Pecking Order Theory, and seems to be supported by the fact that the sample expressed a greater need to ensure adequate financial flexibility (73\%, Q1 in section 3).

A closer analysis of the sample, however, provides a series of indications that seem to refute the applicability of this theory. First of all, the very existence of financial structure targets undermines the theoretical model. 
Furthermore, the possibility of paying a higher credit spread than deemed proper is considered as an important factor by only 38\% of the respondents (Q19 in section 3), and that percentage decreases in the case of smaller companies or companies with lower credit standing, which normally discount more than the others the problem of information asymmetries, and this seems to contradict the model. It is true, however, that this reduction for smaller companies and those with lower credit standing can be explained by the fact that they borrow primarily from the banking channel, which in the Italian context is better able than the market to determine credit risk because of a direct relationship often established over time and because of the use of rating models, introduced in part by the Basel II agreement, which causes the banks to collect and process much information useful for discriminating loan quality. In addition, since banks in Italy are often present in the ownership structures of larger companies, it is logical that borrowing from the banking channel in Italy is less penalized by information asymmetries than borrowing from the capital markets. Lastly, the fact that information disclosure costs seem of little importance in terms of debt (18\%, Q17 in section 3) and, as reported in section 4, in terms of equity (11\%, Q9 in section 6), it would seem to invalidate the use of the Pecking Order Theory to interpret practice.

\subsection{Ownership structure}

Another important aspect in indebtedness decisions is that debt offers the possibility of not altering ownership structures (Q14 in section 3). 47\% of the sample considered this factor important, and this percentage rises to $80 \%$ when "de facto" control is in the hands of an entrepreneur or family, while it drops to $17 \%$ in public companies. Consistently, 40\% (Q13 in section 3) of the sample stated that the willingness of current shareholders to subscribe a capital increase is a significant factor, and if we remove the responses of the public companies ( $0 \%$ ) from this figure, we are left with 55\%, which is in line with the netted percentage of responses to Q14 (60\%). The issue of ownership structure, which will be discussed later on, is also a highly significant factor in equity decisions and, in fact, no less than $71 \%$ of the sample fears the effect in terms of changes to the existing control structure (Q6 in section 6).

\subsection{Other factors}

Three factors in section 3 that were highly regarded by a considerable number of respondents, though not enough to be considered primary decision drivers, are the presence of financial covenants (48\% Q12, which rises to $67 \%$ for companies with ratings lower than BBB), the transactional costs and fees related to the issue of debt (39\%, Q18), and the disciplinary effect of debt in avoiding sub-optimal investments and unnecessary expenditures (36\%, Q16). With regard to this last point, it is important to note that the percentage rises to $67 \%$ in the case of large shareholding-based companies (public companies). This can be explained by the fact that when the ownership is concentrated and above all characterized by the presence of the shareholder inside the company (family capitalism) the direct control of this shareholder can attenuate the control exercised by the market.

Regarding risk management, little significance was attributed to the function of debt as a natural hedging instrument (35\%, Q20). Tail response may depend on the fact that hedging instruments are broadly developed and that better solutions exist for managing risk.

In the preceding section 2, the authors noted that the net debt of principal competitors is not a primary financial target for companies, even if it appears to be a significant secondary target. This observation seems to be confirmed by the fact that only $7 \%$ and $9 \%$ of the CFOs, stated that they are respectively influenced by the debt level (Q9 in section 3) and the liquidity policy (Q7 in section 5) of their competitors. This consideration, though it seems to partially contradict the importance assigned to credit ratings, which are based in part on sector comparisons, suggests that capital structure policies are the result of the contextual conditions of each company 
and the financial risk profile chosen by its management, apart from peer comparisons. As with payout policies, we can therefore conclude that capital structure decisions are apparently not driven by a desire to imitate.

The influence exerted by the possibility that heavy indebtedness might make a company a less attractive takeover target was found to be nil (0\%, Q10 in section 3). Lastly, the bull and bear market phases for M\&A operations (32\%, Q3 in section 5), the possibility of investing liquidity to enjoy favorable tax treatment (22\%, Q5 in section 5), the conviction that shareholders' cash can be better invested by the company (18\%, Q4 in section 5), and avoiding the distribution of cash so as not to send a signal that there are no profitable investment projects (18\%, Q6 in section 5) were found to have little influence on liquidity-related decisions.

\subsection{Short vs. medium/long term debt}

The responses in section 4 of our questionnaire indicate that decisions regarding medium/long-term financing depend to a great extent on a desire to avoid mismatching sources and utilization (96\%, Q2).

As mentioned earlier, the non-revocability of the funding, and thus the greater security in financing investment projects (63\% Q6, which rises to $92 \%$ for companies in the early stages of the life cycle) and the reduced risk of renegotiating the cost of funding in less favorable market situations emerged as the number two driver in the choice between short and medium-long term debt. Lastly, the differences in cost between short- and medium/long-term debt are considered as a decisive driver for $46 \%$ of the sample (Q1), while the request for guarantees (28\%, Q5), the difficulty of access to medium/long-term debt (11\%, Q3), and greater information disclosure (9\%, Q4) are not significant factors.

\section{Equity}

After analyzing the factors that influence decisions regarding the debt and liquidity of Italian listed companies, the data were scrutinized to determine what drives decisions regarding capital increases (see Table 7).

\subsection{Current price of stock and windows of opportunity}

Our analysis of the responses to the 13 questions of section 6 indicates that the predominant factor is the current price of the stock (76\%, Q1). This strong response level is not surprising, since the conviction that shares are overvalued, or at least "fairly valued", is commonly used by management and ownership as a pretext to finance themselves by increasing capital. The markets normally react negatively to the announcement of a new stock issue, since they interpret this as an implicit admission on the part of the insiders (management and main shareholders) that they feel their stock is currently overpriced. Thus, only a "bullish" valuation of the company can more than offset any probable discount.

This percentage, viewed together with the evidence that the general state of the equity market influences the decisions of $60 \%$ of the sample (Q2), and that $60 \%$ feel the prevailing level of interest rates is a strong factor influencing the decision on whether to issue debt or not (Q5 in section 3). It leads us to conclude that companies attribute great importance to the prevailing conditions of the financial markets and their own stock and that, within their pre-constituted financial flexibility, the financing decisions are therefore guided in part, if not exclusively in some cases, by opportunistic market situations that maximize the cost effectiveness of procuring funds. In essence, the theory that companies seek to exploit "windows of opportunity" (Loughran \& Ritter, 1995; Lucas \& McDonald, 1990) seems to find direct confirmation in both debt and equity.

As further evidence of the limited applicability of Pecking Order Theory to reality, it is essential to note from responses to Q1 that the current price of the stock and its possible undervaluation have a much stronger influence 
on the blue chips (88\%) and the larger (89\%) and investment grade (92\%) companies, i.e., those that should be less affected by information asymmetries than on other companies.

Table 7 Responses section 6 "Decisions regarding equity via capital increase”

\begin{tabular}{|c|c|c|c|c|c|c|c|c|c|c|c|c|c|}
\hline Decisions regarding equity via capital increase & & & & Impo & ortant & or very & impor & ttant re & sponse & s (\%) & & & \\
\hline Average market response & Q1 & Q2 & Q3 & Q4 & Q5 & Q6 & Q7 & Q8 & Q9 & Q10 & Q11 & Q12 & Q13 \\
\hline Market & 75.6 & 60.0 & 59.1 & 51.1 & 18.2 & 71.1 & 13.3 & 28.9 & 11.1 & 44.4 & 23.3 & 20.5 & 9.5 \\
\hline Stock market segment & & & & & & & & & & & & & \\
\hline Blue chip & 87.5 & 68.8 & 66.7 & 56.3 & 12.5 & 62.5 & 6.3 & 18.8 & 6.3 & 43.8 & 25.0 & 31.3 & 21.4 \\
\hline Standard & 70.0 & 70.0 & 60.0 & 40.0 & 0.0 & 80.0 & 10.0 & 50.0 & 0.0 & 60.0 & 22.2 & 10.0 & 0.0 \\
\hline Star & 88.9 & 44.4 & 44.4 & 44.4 & 44.4 & 66.7 & 11.1 & 44.4 & 0.0 & 33.3 & 0.0 & 11.1 & 0.0 \\
\hline Other & 50.0 & 25.0 & 75.0 & 50.0 & 0.0 & 75.0 & 25.0 & 0.0 & 50.0 & 50.0 & 66.7 & 33.3 & 25.0 \\
\hline Sector & & & & & & & & & & & & & \\
\hline Telecommunications, Tech. \& Media & 66.7 & 66.7 & 66.7 & 50.0 & 0.0 & 83.3 & 0.0 & 33.3 & 0.0 & 66.7 & 80.0 & 0.0 & 0.0 \\
\hline Utilities & 100.0 & 66.7 & 66.7 & 66.7 & 16.7 & 66.7 & 16.7 & 0.0 & 16.7 & 50.0 & 33.3 & 33.3 & 33.3 \\
\hline Consumer goods & 80.0 & 60.0 & 60.0 & 60.0 & 20.0 & 80.0 & 20.0 & 40.0 & 0.0 & 40.0 & 0.0 & 20.0 & 0.0 \\
\hline Industrial & 69.2 & 46.2 & 41.7 & 46.2 & 23.1 & 53.8 & 0.0 & 38.5 & 0.0 & 38.5 & 7.7 & 30.8 & 9.1 \\
\hline Other & 88.9 & 66.7 & 77.8 & 33.3 & 12.5 & 77.8 & 22.2 & 33.3 & 22.2 & 44.4 & 12.5 & 11.1 & 11.1 \\
\hline Revenues ( $€$ millions) & & & & & & & & & & & & & \\
\hline $100<\mathrm{R}<500$ & 66.7 & 47.6 & 40.0 & 33.3 & 35.7 & 53.3 & 20.0 & 47.6 & 6.7 & 33.3 & 7.7 & 14.3 & 7.1 \\
\hline $500<\mathrm{R}<1,000$ & 66.7 & 100.0 & 66.7 & 33.3 & 16.7 & 100.0 & 0.0 & 50.0 & 16.7 & 50.0 & 50.0 & 16.7 & 16.7 \\
\hline $\mathrm{R}>1,000$ & 88.9 & 66.7 & 70.6 & 55.6 & 11.1 & 61.1 & 5.6 & 16.7 & 5.6 & 44.4 & 22.2 & 27.8 & 18.8 \\
\hline Life cycle phase & & & & & & & & & & & & & \\
\hline Fast growth & 76.9 & 69.2 & 69.2 & 69.2 & 8.3 & 84.6 & 15.4 & 30.8 & 23.1 & 53.8 & 25.0 & 30.8 & 23.1 \\
\hline Stability & 70.6 & 58.8 & 52.9 & 35.3 & 17.6 & 64.7 & 5.9 & 29.4 & 0.0 & 29.4 & 29.4 & 6.3 & 0.0 \\
\hline Maturity & 100.0 & 44.4 & 62.5 & 44.4 & 22.2 & 55.6 & 11.1 & 33.3 & 0.0 & 66.7 & 0.0 & 33.3 & 14.3 \\
\hline Control structure & & & & & & & & & & & & & \\
\hline Legal control by entreprene & 76.5 & 47.1 & 52.9 & 41.2 & 11.8 & 64.7 & 11.8 & 35.3 & 0.0 & 29.4 & 12.5 & 17.6 & 0.0 \\
\hline De facto control by entrepreneur(s) or family & 75.0 & 50.0 & 100.0 & 100.0 & 50.0 & 100.0 & 25.0 & 25.0 & 0.0 & 100.0 & 25.0 & 33.3 & 0.0 \\
\hline Widely-owned (public company) & 50.0 & 50.0 & 33.3 & 50.0 & 33.3 & 50.0 & 0.0 & 33.3 & 0.0 & 16.7 & 16.7 & 0.0 & 0.0 \\
\hline Legal control by other company & 100.0 & 66.7 & 83.3 & 0.0 & 0.0 & 66.7 & 16.7 & 16.7 & 33.3 & 83.3 & 40.0 & 33.3 & 33.3 \\
\hline Other & 100.0 & 100.0 & 66.7 & 83.3 & 0.0 & 83.3 & 0.0 & 33.3 & 16.7 & 50.0 & 33.3 & 33.3 & 33.3 \\
\hline Positioning in the control structure & & & & & & & & & & & & & \\
\hline Parent of group of companies & 77.4 & 61.3 & 63.3 & 51.6 & 20.0 & 71.0 & 9.7 & 32.3 & 6.5 & 38.7 & 20.0 & 20.0 & 6.9 \\
\hline Subsidiary of an unlisted parent & 83.3 & 66.7 & 33.3 & 33.3 & 0.0 & 66.7 & 16.7 & 16.7 & 16.7 & 66.7 & 33.3 & 16.7 & 16.7 \\
\hline Rating & & & & & & & & & & & & & \\
\hline Greater than or equal to $\mathrm{BBB}$ & 91.7 & 75.0 & 66.7 & 50.0 & 8.3 & 75.0 & 8.3 & 16.7 & 16.7 & 58.3 & 41.7 & 33.3 & 25.0 \\
\hline Less than BBB & 100.0 & 100.0 & 33.3 & 33.3 & 0.0 & 33.3 & 0.0 & 33.3 & 0.0 & 66.7 & 0.0 & 0.0 & 0.0 \\
\hline Unrated & 70.8 & 45.8 & 60.9 & 50.0 & 21.7 & 70.8 & 12.5 & 37.5 & 4.2 & 37.5 & 13.6 & 17.4 & 4.8 \\
\hline Existence of stock option & & & & & & & & & & & & & \\
\hline Yes, significant & 66.7 & 50.0 & 58.3 & 33.3 & 25.0 & 41.7 & 0.0 & 25.0 & 0.0 & 25.0 & 16.7 & 16.7 & 8.3 \\
\hline Yet, not significant & 88.9 & 66.7 & 62.5 & 66.7 & 25.0 & 77.8 & 22.2 & 22.2 & 11.1 & 55.6 & 12.5 & 33.3 & 12.5 \\
\hline No & 83.3 & 61.1 & 61.1 & 50.0 & 5.6 & 83.3 & 11.1 & 38.9 & 11.1 & 55.6 & 29.4 & 17.6 & 12.5 \\
\hline
\end{tabular}

\subsection{The ownership structures in Italy and their influence on equity decisions}

The potential dilutive effect on the existing control structure, if the controlling shareholders lack the resources or the desire to increase capital (71\%, Q6), was the second most influential factor in equity decisions. As we shall point out further on, this is one of the factors that most differentiates decision-making processes in 
Italy from those of US-UK companies. The most common forms of control in Italy, family ownership and control through shareholder agreements, make the current controlling shareholders particularly sensitive to potential dilutive effects, a definitely minor phenomenon in the US and UK, where public companies prevail. As confirmation of this, the public companies were less attentive to this aspect (50\%), while $100 \%$ of the companies controlled "de facto" by an entrepreneur or a family deemed this factor as very influential.

\subsection{Financial structure targets also condition equity decisions}

It is interesting to note that the desire to maintain financial structure targets is the third most influential driver (59\%, Q3). As in the case of decisions regarding debt, this factor is even more important, if we consider only the responses by the companies that stated they had financial structure targets (69\%).

It should be emphasized that companies that declared which had one or more targets are definitely keener not to deviate from the targets when operating on debt rather than on equity (89\% vs. $69 \%$ ), demonstrating a conviction, also supported by Philippon (2003) and Servaes and Tufano (2006), that the "payoffs" deriving from optimization of capital structure are asymmetrical, in the sense that the costs associated with third having less debt than deemed optimal are always lower than those associated with a higher-than-optimal level. This would explain why companies prefer to position themselves at sub-optimal, more conservative debt levels, as long as they protect against the risk of finding themselves with an overly-indebted structure and pay the consequences in terms of costs and less financial flexibility.

\subsection{Influence of the "fallacious" dilutive effect on EPS}

The fifth factor that was selected as most influential was the potential dilutive effect on EPS (51\%, Q4). Although according to a few scholars, particularly Brealy and Myers, the conviction that the issue of shares dilutes EPS may be misleading, since it does not occur if the company employs the resources in investments with returns equal to or greater than the current ones, this conviction is known to be strong among management. It is said to be attributable to the immediate impact on EPS that an increase of the number of shares may have, if earnings do not rise proportionally and therefore to the fear that this will consequently jeopardize the trading price of the shares. The blue chips and large companies are those that, in their respective categories, are most influenced by this potential effect (56\%), though for them, also, it only ranks fifth in order of importance among the drivers.

\subsection{The illiquidity of the stock}

The last factor that was assigned some importance was the illiquidity of the stock, especially for companies under the "de facto" control of entrepreneurs and/or families and those legally controlled by other companies (44\%, Q10). This phenomenon appears to be the direct consequence of the common Italian ownership structures, which often result in a scarcity of float, and thus, an unsatisfactory state of stock liquidity, leading the market to apply some level of liquidity discount. The evidence provided by the data is that companies with widespread ownership, a marked minority in Italy, express little concern with this factor (17\%).

\subsection{Factors of minor influence}

Thus far, we have considered the most important factors. Let us now look briefly at those that to a varying extent have less impact on equity decisions. Only $29 \%$ of the sample felt that issuing shares might send a better signal to the financial community than issuing debt (Q8). Contrary to payout policies, capital structure decisions therefore seem uninfluenced by any signaling implications. Furthermore, only $23 \%$ of the sample stated that the transactional costs and fees involved in issuing new equity are a significant factor (Q11). It is interesting to note that although transaction costs in the case of debt are also not a primary driver of choice, they were deemed more significant. This might be attributable to the fact that these costs, though generally more significant in the issue of 
shares, have a greater incidence in cost evaluations with the use of debt than with equity, where the advantage depends primarily on the conviction that there is a proper pricing of the stock, apart from the dilutive effect on current shareholders. Other factors of little influence are the desire to assign shares to employees to service stock option plans (Q5, 18\%, 25\% for companies with some stock option plan), the tax regime of the shareholders (Q7, $13 \%)$, and the costs of information disclosure (Q9, 11\%). Lastly the US SOx and the corresponding Italian law 262/05 do not seem to be a deterrent to issuing equity in a regulated market, because only 10\% (Q13 in section 6) indicated this factor as influential. Worth to notice that only a very few Italian companies are subject to SOX regulation and Italian law 262/05, which corresponds to the US SOX-came into force only in 2007.

\section{Financing abroad}

Of the 76 companies in our sample, only 28 responded to the questions in this section, which seems to indicate a domestic focus of Italian companies, at least at the financial level (see Table 8).

Table 8 Responses section 7 "Decisions between domestic and foreign financing"

\begin{tabular}{|c|c|c|c|c|c|c|c|}
\hline \multirow{2}{*}{$\begin{array}{l}\text { Decision between domestic and foreign financing } \\
\text { Average market response } \\
\end{array}$} & \multicolumn{7}{|c|}{ Important or very important responses (\%) } \\
\hline & Q1 & Q2 & Q3 & Q4 & Q5 & Q6 & Q7 \\
\hline Market & 38.9 & 63.2 & 84.2 & 36.8 & 5.3 & 42.1 & 47.4 \\
\hline \multicolumn{8}{|l|}{ Stock market segment } \\
\hline Blue chip & 36.4 & 54.5 & 81.8 & 9.1 & 9.1 & 45.5 & 36.4 \\
\hline Standard & 0.0 & 66.7 & 100.0 & 66.7 & 0.0 & 33.3 & 66.7 \\
\hline Star & 0.0 & 100.0 & 100.0 & 0.0 & 0.0 & 100.0 & 100.0 \\
\hline Other & 0.0 & 100.0 & 100.0 & 100.0 & 0.0 & 0.0 & 0.0 \\
\hline \multicolumn{8}{|l|}{ Sector } \\
\hline Telecommunications, Tech. \& Media & 0.0 & 66.7 & 100.0 & 33.3 & 0.0 & 33.3 & 66.7 \\
\hline Utilities & 25.0 & 50.0 & 50.0 & 0.0 & 0.0 & 0.0 & 25.0 \\
\hline Consumer goods & 50.0 & 0.0 & 120.0 & 70.0 & 0.0 & 70.0 & 0.0 \\
\hline Industrial & 50.0 & 75.0 & 100.0 & 0.0 & 25.0 & 100.0 & 75.0 \\
\hline Other & 0.0 & 100.0 & 100.0 & 66.7 & 0.0 & 33.3 & 33.3 \\
\hline \multicolumn{8}{|l|}{ Revenues (€ millions) } \\
\hline $100<\mathrm{R}<500$ & 0.0 & 100.0 & 100.0 & 0.0 & 0.0 & 100.0 & 100.0 \\
\hline $500<\mathrm{R}<1,000$ & 0.0 & 66.7 & 100.0 & 66.7 & 0.0 & 33.3 & 33.3 \\
\hline $\mathrm{R}>1,000$ & 36.4 & 58.3 & 83.3 & 16.7 & 8.3 & 41.7 & 41.7 \\
\hline \multicolumn{8}{|l|}{ Life cycle phase } \\
\hline Fast growth & 14.3 & 57.1 & 71.4 & 28.6 & 14.3 & 42.9 & 14.3 \\
\hline Stability & 16.7 & 71.4 & 100.0 & 28.6 & 0.0 & 42.9 & 71.4 \\
\hline Maturity & 100.0 & 50.0 & 100.0 & 0.0 & 0.0 & 50.0 & 50.0 \\
\hline \multicolumn{8}{|l|}{ Control structure } \\
\hline Legal control by entrepreneur(s) or family & 50.0 & 75.0 & 100.0 & 50.0 & 0.0 & 50.0 & 50.0 \\
\hline De facto control by entrepreneur(s) or family & 100.0 & 100.0 & 100.0 & 50.0 & 0.0 & 50.0 & 100.0 \\
\hline Widely-owned (public company) & 33.3 & 0.0 & 100.0 & 0.0 & 0.0 & 33.3 & 33.3 \\
\hline Legal control by other company & 0.0 & 100.0 & 100.0 & 100.0 & 0.0 & 0.0 & 0.0 \\
\hline Other & 0.0 & 66.7 & 66.7 & 0.0 & 16.7 & 50.0 & 33.3 \\
\hline
\end{tabular}




\begin{tabular}{|c|c|c|c|c|c|c|c|}
\hline Parent of group of companies & 28.6 & 60.0 & 86.7 & 20.0 & 6.7 & 46.7 & 46.7 \\
\hline Subsidiary of an unlisted parent & 0.0 & 100.0 & 100.0 & 100.0 & 0.0 & 0.0 & 0.0 \\
\hline \multicolumn{8}{|l|}{ Rating } \\
\hline Greater than or equal to BBB & 25.0 & 66.7 & 77.8 & 22.2 & 11.1 & 22.2 & 44.4 \\
\hline Less than BBB & 0.0 & 0.0 & 100.0 & 0.0 & 0.0 & 100.0 & 0.0 \\
\hline Unrated & 40.0 & 80.0 & 100.0 & 40.0 & 0.0 & 60.0 & 60.0 \\
\hline \multicolumn{8}{|c|}{ Existence of stock option plans/stock grants } \\
\hline Yes, significant & 76.9 & 46.2 & 23.1 & 0.0 & 23.1 & 0.0 & 7.7 \\
\hline Yet, not significant & 66.7 & 44.4 & 33.3 & 11.1 & 11.1 & 33.3 & 0.0 \\
\hline No & 72.2 & 33.3 & 29.4 & 35.3 & 33.3 & 27.8 & 16.7 \\
\hline
\end{tabular}

Our analysis indicates that companies that obtain financing outside the domestic market are driven primarily by a desire to diversify their funding in markets they consider globalized (84\%, Q3), and secondarily, by a desire to gain company recognition outside their home countries $(63 \%$, Q2). The latter rises sharply for smaller companies ( $100 \%$ for companies with a revenue not exceeding $€ 500$ million), which have a greater need to make themselves known and which, unlike larger firms, consider IAS/IFRS (100\% Q6, 42\% the sample as a whole) as an important contribution in facilitating financial communication. These factors seem to prevail over the desire to seize favorable economic conditions (only 39\%, Q1), unlike the situation in the domestic market, where this concern is much greater (60\%, Q5 in section 3). Lastly, the possibility of capturing tax benefits (47\%, Q7), and secondarily, the harmonization introduced by Basel II (37\%, Q4) seem moderately important stimuli, while investment in financial communication is not a significant criterion for respondents (5\%, Q5).

\section{Benchmarking with other countries/studies}

A number of studies have been conducted on financial structure policies, some of which cover a number of countries and topics, while others, such as the current study, focus on one geographical area or one specific topic. In our benchmarking, we decided to make particular reference to two studies: The first is the aforesaid work of Graham and Harvey (2001), while the second is that of Bancel and Mittoo (2002), a study that used the same investigative methods as Graham and Harvey in 16 European countries, including Italy ${ }^{3}$ and is the contribution most cited in international studies on capital structure.

Also worthy of note is the research conducted by Servaes and Tufano (2006), analyzing the financial structure decisions of listed and unlisted companies in America, Europe, Asia and Oceania. The authors prefer not to benchmark with this last study because of the different organization of the questionnaire, which did not permit ready comparison of results.

We shall now point out the principal similarities and differences between the results of our work and the studies of Graham and Harvey (2001) and of Bancel and Mittoo (2002). The factors not mentioned, for the sake of brevity, were assigned similar importance in the two studies.

\subsection{Flexibility financial and minimizing the cost of capital}

Financial flexibility was also found to be the factor that most influences decisions regarding debt for $59 \%$ of

\footnotetext{
${ }^{3}$ The countries analyzed by the two authors, besides Italy, were France, Belgium, Greece, Portugal, Spain, the Netherlands, Germany, Austria, Switzerland, Denmark, Finland, Norway, Sweden, United Kingdom, and Ireland.
} 
the respondents in the Graham and Harvey study and 91\% in the Bancel and Mittoo study. Even in contexts different from Italy, the key to interpreting capital structure decisions there seems to be, therefore, a desire on the part of companies to minimize the cost of capital by exploiting the lower cost of debt, provided they could maintain adequate financial flexibility to satisfy the needs of investment policy and, then, payout policy. As part of this quest for flexibility, companies in America and the 16 countries analyzed by Bancel and Mittoo stated that they were extremely attentive to exploiting windows of opportunity in both the debt and equity markets.

\subsection{Importance of credit ratings}

The second most selected factor in both studies was the importance of credit ratings assigned by the agencies (57\% in Graham and Harvey and 73\% in Bancel and Mittoo), whereas it appeared as the eleventh in the study, selected by $44 \%$ of the respondents to our questionnaire. In reality, if we consider only those companies in our sample that have agency-assigned ratings, the results of our survey are totally in line with the other two (72\%). The difference can thus be attributed more to the peculiarity of our sample (over $61 \%$ with no rating) than to different decision-making patterns.

Unlike our survey, the two studies do not include in their options for the ratings assigned by banks, largely the result of recent developments introduced by the Basel II agreement. If we also consider the importance which has assumed for unrated companies (61\%, Q7 in section 3), the significance attributed to ratings is even more accentuated. The moderate percentages associated in the section 2 with credit rating as a target of capital structure policy (26\% primary, 20\% secondary) should not be misleading, since the two ratios most selected (Net Debt/EBITDA and Net Debt/Equity) are still utilized both by rating agencies and by banks to determine creditworthiness, and they are also easier to use within a company, since they are the result of individual ratios as opposed to composite ratios, such as credit ratings.

\subsection{Presence of financial targets}

Graham and Harvey's research indicates that American companies also use financial structure targets to orientate their decisions (only 19\% stated they had none). It is important to note that, as in the Italian case, the larger and investment grade companies in the U.S. are also those that make greatest use of targets. The absence of an explicit question regarding the types of target prevents us from making a direct comparison with our study. Regarding the Bancel and Mittoo study, they also had no direct question on the subject. But the evidence that 59\% of the sample declared that maintaining the debt-to-equity target influences decisions on equity suggests that the use of financial targets is also a widespread practice identified in that study.

\subsection{The ownership structures type of the Italian market influence capital structure decisions}

The largest difference between our research and the two benchmark research studies is definitely the different role played by ownership structure in capital structure decisions. The possible dilutive effect of a capital increase on controlling shareholders, when they lack the available resources or do not wish to invest, received a much higher response level here than in the other countries (29\% in Graham and Harvey and 50\% in Bancel and Mittoo, eighth and sixth most selected factor, respectively, vs. $71 \%$ in our study, the second most influential factor). In the case of the Bancel and Mittoo study, it should be pointed out that the larger consensus obtained for this factor is due to the presence of countries like Germany, Italy, France and Spain in the sample, which typically have fewer public companies than the United States and United Kingdom, which, in fact, showed the lowest percentages.

The macro trade-off between minimizing the cost of capital and the need to ensure adequate financial flexibility thus gains a third consideration in countries like Italy, i.e., the attention to not allowing financial decisions to modify the "status quo" of the ownership structure. This is the root cause of the greater dependence of 
domestic companies, especially the small-midsize ones, on the banking system (often a compromise in the need for new financial resources while maintaining control structures) and of a certain "financial asphyxia" compared to international competitors, given the importance of that constraint.

\subsection{EPS dilution more important abroad than in Italy}

Another major difference between the study and the two mentioned above is the different weight attributed to the potential dilutive effect of capital increases on EPS. This was the principal factor influencing equity decisions in both the Graham and Harvey (for 69\% of the respondents) and Bancel and Mittoo (for $66 \%$ of the respondents) studies. While in the survey, it was only the fifth most selected factor (for $48 \%$ of the respondents, which rises to $56 \%$ in the case of the blue chips). It should be noted, in this regard, that in our previous study on payout policies, Italian companies showed that they were much less attentive than their American colleagues to the potential accretive effect on EPS that can be obtained through buybacks. This different approach of Italian executives can probably be attributed to the fact that the majority of investors in many small-midsize companies are typically Italian and less sensitive to this indicator, while it is highly regarded in the US-UK. This is supported by the fact that, the blue chip companies, whose ownership base also contains many international investors, gave greater emphasis to the effects on EPS.

\subsection{Different objectives of financing abroad}

Differences were noted in the criteria that guide the decision to seek financing abroad, regarding both risk management (86\% Graham and Harvey and 67\% Bancel and Mittoo vs. 34\% in our sample) and the desire to keep financing close to the entity that uses it (63\% Graham and Harvey and 67\% in Bancel and Mittoo vs. $27 \%$ in our sample) - This difference can be explained by the need for these companies to gain recognition abroad and the relatively smaller degree of financial decentralization in Italian groups, often international but not multinational.

\subsection{Other minor differences}

Less important differences include greater attention to the indebtedness level of competitors (23\% in both Graham and Harvey and Bancel and Mittoo vs. 7\% in our sample) and the influence of the desire to assign shares to employees to service stock option plans (53\% in Graham and Harvey and $44 \%$ in Bancel and Mittoo vs. $12 \%$ in the case, $25 \%$ for companies with significant plans).

Lastly, the two studies did not include a question on the influence of liquidity/illiquidity of company stock in equity decisions. It is reasonable to expect that this factor would be much more influential in Italy than in other countries, such as the US and UK, given the presence of a plethora of less-than-large companies in the Italian financial market with family control and limited float, especially if compared with the large public companies in the US and UK markets.

\section{Conclusions}

Our survey revealed that the Pecking Order Theory and the Trade-off Theory models are of limited applicability to the Italian market; likewise, the "Inertia Theory" did not seem applicable, since the companies expressed an active attitude toward managing capital structure. Rather, the principle that inspires capital structure policies was found to be a desire to maintain over time the financial flexibility necessary to combine effectively capital structure policy with the other two levers of value creation: first of all, investment policy, followed by payout policy. These three value creation levers are attributed to the autonomous merit of value drivers, but the empirical analysis revealed a clear hierarchy that links liability policy (capital structure and payout) to asset policy 
(investments), leading companies to make sub-optimal financial structure decisions that may not minimize the weighted average cost of capital, though ensuring the financial flexibility necessary to activate their principal lever of value creation, investment policy, effectively and without excessive constraints.

Financial flexibility was also found to be valuable for exploiting windows of opportunity and, not coincidentally, the companies showed that they are particularly attentive to exploiting favorable situations both in the debt market (low interest rates) and in the equity market (bullish pricing of their stock).

The trade-off between minimizing the cost of capital and financial flexibility leans on financial targets, primarily of an accounting nature (Net Debt/EBITDA and Net Debt/Equity) and not in market terms. These are the financial targets companies seek to adhere to, especially by operating with debt, considering that maintaining an adequate level of financial flexibility leads them to believe that the costs associated with a sub-optimal level of debt which are still less than those associated with having a higher-than-optimal level.

From the standpoint of international benchmarking, the decision-making patterns of Italian listed companies were found to be generally in line with those of American, British and other European companies, with a different influence of ownership structure. In the Italian case, the trade-off between minimizing the cost of capital and financial flexibility is often joined by a third factor that is often decisive, the potential dilutive effects that company financial decisions may have on controlling shareholders. In fact, in a form of capitalism like Italy's, characterized by companies under family control or "de facto" control (through shareholder agreements or cascade structures), the potential dilutive effects on the controlling shareholders, when they lack the resources and/or are unwilling to invest further capital, are extremely influential factors in equity decisions (and also important in debt decisions) of listed companies compared with their marginal or neutral importance abroad. The attention to not allowing financial decisions to modify the "status quo" of the ownership structure determines a greater dependence of domestic companies, especially the small-midsize ones, on the banking system (often a compromise in the need for new financial resources while maintaining control structures) and a certain "financial asphyxia" compared to international competitors.

Furthermore, in the previous study on payout policy, the authors stressed the importance played by ownership structure and the typical corporate governance systems, as interpreted the lower propensity of companies to defend their dividend levels as the result of a weakening of their role as an instrument of control over management in the block holder-based Italian system. This additional observation on capital structure is further evidence that ownership structures and typical corporate governance systems are key to interpreting the differences in financial decisions of companies operating in countries with different ownership characteristics. That is why we believe that the results of our research are probably not limited to the Italian market, but could also be extended to the countries where companies are held by few shareholder, also through shareholder agreement often including banks.

At the end of the study, many questions remain still unanswered.

Does the market reward this constructed financial flexibility to the detriment, "ceteris paribus", of a higher cost of capital? If so, does the premium consist of more aggressive projections of future cash flows, considering a greater capacity to sustain profitable investment plans? Moreover, does this possible premium vary, perhaps, in relation to general market sentiment or to more or less "bullish" market phases, somehow incorporating in the enterprise value the ability of the financially flexible company to be active in terms of acquisitions and/or investments? Or, rather, can sub-optimal leverage be interpreted as a greater reserve of elasticity and thus as greater value to attribute to a more flexible company compared to one that is less flexible but has the same 
expected financial flows?

These are questions which the authors could be the point of departure for further research and studies regarding financial structure policies and, more generally, the combined analysis of the three value creation levers: investments, payout policy and capital structure.

\section{References:}

Bancel, F. \& Mittoo, U. R.. (2004, Winter). Cross-country determinants of capital structure choice: A survey of European signatures. Financial Management, 33(4).

Dallocchio, M., Tzivelis, D. \& Vinzia, M.. (2007). La payout policy, la prospettiva del mercato finanziario Italiano. SDA Bocconi Working Paper.

Donaldson, G.. (1969). Strategy for financial mobility. Boston, Division of Research, Harvard Graduate School of Business Administration.

Graham, J. \& Harvey, C.. (2001). The theory and practice of corporate finance: Evidence from the field. Journal of Financial Economics, 60, 187-243.

Loughran, T. \& Ritter, J. R .. (1995). The new issues puzzle. Journal of Finance, 50, 23-52.

Lucas, D. J. \& McDonald, R. L.. (1990). Equity issues and stock price dynamics. Journal of Finance, 45, 1019-1043.

Miller, M. H.. (1977). Debt and taxes. Journal of Finance, 32, 261-275.

Modigliani, F. \& Merton, M.. (1958). The cost of capital, corporation finance and the theory of investment. American Economic Review, 48, 261-297.

Modigliani, F. \& Merton, M.. (1963). Corporate income taxes and the cost of capital: A correction. American Economic Review, 53, 433-443.

Myers, S.C. \& Majiluf, N.. (1984). Corporate financing and investment decisions when firms have information that investors do not have. Journal of Financial Economics, 13, 187-224.

Peyer, U. C. \& Shivdasani, A.. (2001). Leverage and internal capital markets: Evidence from leveraged recapitalizations. Journal of Financial Economics, 59, 477-515.

Philippon, T.. (2003). Revealed preferences for corporate leverage. Working paper, New York University.

Pagano, M., Panetta, F. \& Zingales, L.. (1998, February). Why do companies go public? An empirical analysis. Journal of Finance.

Scott, .H.. (1976). A theory of optimal capital structure. Bell Journal of Economics, 7(1), 33-54.

Servaes, H. \& Tufano, P.. (2006). The theory and practice of corporate capital structure: In: Global survey of corporate financial policies and practices. Deutsche Bank Research.

(Edited by Ruby and Chris)

Appendix A1 Questions section 2-Preferred forms of financing and financial structure targets

Preferred forms of financing and financial structure targets

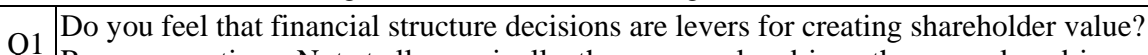

Q1 Response options: Not at all, marginally, they are a value driver, they are a key driver

Q2 Do you feel that financial structure decisions are levers for creating bondholder value?

Q2 Response options: Not at all, Marginally, They are a value driver, They are a key driver

What order of importance do you give to these value creation drivers? (1, 2, 3 or 0 if not deemed a driver)

Q3 Response options: Investment policy (including M\&A activity), Financial structure decisions, Payout policies (dividends and buybacks)

What order of preference (1 high - 5 low) so you attribute to the following sources, assuming that each of them is feasible?

Q4 Response options: Self-financing, Capital increases, Debt via the bank channel, Debt via the market (bond issuance), Hybrid forms of financing (e.g. convertibles)

Does the company have one or more financial structure targets by which it measures itself when making financial structure

Q5 decisions?

Response options: Yes, No

If NO, no target is defined because (even more than one choice)

Q6 Response options: Company structurally liquid; Uses debt only when self-financing is insufficient; Financial structure decisions are made based on market opportunities; Strong variability (growth, results, cash flow, etc.) precludes the setting of targets)

If YES, what targets? (P for primary, S for secondary)

Q7 Response options: Net Debt/Market Cap, Net Debt/Equity, Net Debt/EBITDA, EBITDA/Financial Expense Financial, Credit Rating Target, Net Debt of principal competitors, Other

Q8 If YES, the target(s) is(are):

Q8 Response options: A strong constraint over time, reviewable medium-term (e.g., 3 years), reviewable short-term 


\section{Appendix A2 Questions section 3-Decisions regarding debt}

\begin{tabular}{|c|c|}
\hline & Importance of the following factors \\
\hline Q1 & $\begin{array}{l}\text { Financial flexibility (debt level is kept low so as to have potential financial resources that can be used to fund emerging new } \\
\text { projects) }\end{array}$ \\
\hline Q2 & The conviction that debt is the less costly form of financing \\
\hline Q3 & Maintain financial structure targets \\
\hline Q4 & The tax advantage of deductible borrowing costs (tax shields) \\
\hline Q5 7 & The prevailing level of interest rates \\
\hline Q6 $\mathrm{I}$ & Desire not to alter the credit rating (assigned by agencies) \\
\hline Q7 & Desire not to alter the credit rating (assigned by banks) \\
\hline Q8 & The volatility of future income and cash flows \\
\hline Q9 & The debt level of competitors \\
\hline Q10 I & Desire to have heavy indebtedness so as to be a less attractive target for a hostile takeover \\
\hline Q11 & Ability to maintain current level of dividends and those of the payout policy \\
\hline Q12 $\mathrm{I}$ & Presence of financial covenants \\
\hline Q13: & The willingness of current shareholders to subscribe a capital increase \\
\hline Q14 & The possibility of not changing the current control structure \\
\hline Q15 1 & The potential bankruptcy costs (financial distress costs) associated with a more aggressive financial structure \\
\hline Q16 ${ }_{\mathrm{i}}^{\mathrm{T}}$ & $\begin{array}{l}\text { The disciplinary effect of debt on management actions (commitment to utilize flows to repay debt, avoiding sub-optimal } \\
\text { investments or unnecessary expenditures) }\end{array}$ \\
\hline Q17 1 & The costs of disclosing information to the market \\
\hline Q18 1 & The transactional costs and fees required \\
\hline Q19] & The potential credit spread vs. the fair spread \\
\hline Q20 $\mathrm{F}$ & Risk management, indebtedness in a foreign currency can hedge credit positions in that currency \\
\hline
\end{tabular}

\section{Appendix A3 Questions section 5-Decisions regarding liquidity}

\begin{tabular}{|l|l|}
\hline \multicolumn{2}{|c|}{ Importance of the following factors } \\
\hline Q1 & Financial flexibility, i.e., having cash available to finance possible investments, including M \& A opportunities \\
\hline Q2 & Having a reserve of elasticity to ensure reaching payout (dividend) objectives \\
\hline Q3 & The market phase (bull/bear period for M \& A operations) \\
\hline Q4 & Conviction we could invest cash better than our shareholders \\
\hline Q5 & The possibility of investing cash to obtain favorable tax treatment \\
\hline Q6 & Not distributing liquidity to avoid signaling to the market a lack of profitable investment projects \\
\hline Q7 & The liquidity level of competitors \\
\hline Q8 & A desire to reassure our shareholders about the company’s low financial risk (conservative financial structure) \\
\hline
\end{tabular}

\section{Appendix A4 Questions section 4-Decisions between short- and medium/ long-term debt}

\begin{tabular}{|l|l|}
\hline \multicolumn{2}{|l|}{ Importance of the following factors } \\
\hline Q1 & The differences in the cost of financing \\
\hline Q2 & Desire to have debts with the same duration as the assets financed (avoid mismatching) \\
\hline Q3 & Difficulty of accessing medium/long-term financing \\
\hline Q4 & Greater information disclosure for medium/long-term financing \\
\hline Q5 & Request for guarantees by the banks \\
\hline Q6 & Non-revocability of medium/long-term financing and thus greater security \\
\hline
\end{tabular}


Appendix A5 Questions section 6-Decisions regarding equity via capital increase

\begin{tabular}{|l|l|}
\hline \multicolumn{2}{|l|}{ Importance of the following factors } \\
\hline Q1 & Current stock price \\
\hline Q2 & General state of the equity market \\
\hline Q3 & Maintain financial structure targets \\
\hline Q4 & Dilutive effects on earnings per share \\
\hline Q5 & Desire to assign shares to employees, to service a stock option plan \\
\hline Q6 & $\begin{array}{l}\text { The potential dilutive effect on the existing control structure (when the controlling shareholders lack the resources or the desire } \\
\text { to increase capital) }\end{array}$ \\
\hline Q7 & The tax regime of the shareholders \\
\hline Q8 & Issuing shares sends a better signal to the financial community than issuing new debt \\
\hline Q9 & The costs of information disclosure \\
\hline Q10 & The liquid/illiquid status of the stock \\
\hline Q11 & The transactional costs and fees for issuing new equity \\
\hline Q12 & The Vietti reform, which permits greater flexibility in the characteristics of stock issues (vote, dividend, etc.) \\
\hline Q13 & The Sarbanes-Oxley regulation, 262/05, etc. are deterrents to issuing equity in regulated markets \\
\hline
\end{tabular}

Appendix A6 Questions section 7-Decisions between domestic and foreign financing

\begin{tabular}{|l|l|}
\hline \multicolumn{2}{|l|}{ Importance of the following factors } \\
\hline Q1 & When advantageous, financing must also be sought in foreign countries where we have a presence \\
\hline Q2 & Operating with foreign financial markets is one way to gain company recognition abroad \\
\hline Q3 & The financial markets are globalized, financing should be extended on an international scale \\
\hline Q4 & Basel II makes risk profiling and pricing processes more uniform in the developed countries \\
\hline Q5 & Investment in financial communication makes the extension of financing abroad less attractive \\
\hline Q6 & The IAS facilitate financial statement interpretation when operating outside the domestic market, thus reducing disclosure costs \\
\hline Q7 & Operating in foreign markets can bring tax benefits \\
\hline
\end{tabular}

